\title{
Influência de métricas dinâmicas na avaliação do aproveitamento da luz natural em clima tropical
}

\author{
Dynamic metrics influence on the assessment of \\ daylighting potential use at tropic climate
}

\section{Alice Ruck Drummond Dias J uliana Portela Vilar Carvalho Viviane Diniz Hazboun Aldomar Pedrini}

\section{Resumo}

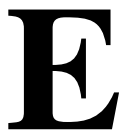

ste artigo visa contribuir para a discussão das métricas dinâmicas Maximum Daylight Autonomy (Damax [Autonomia de Luz Natural Máxima]) e Useful Daylight Illuminance (UDI [Iluminância Natural Útil]) em análises de desempenho da luz natural em clima tropical. Devido à alta luminosidade nos trópicos, os resultados dessas métricas podem não fornecer indicações adequadas de uniformidade e disponibilidade da luz no ambiente. Foram realizadas simulações dinâmicas no software Daysim de salas multiúso com um sistema de abertura sombreado. Os modelos combinam fator de céu visível (FCV alto, médio e baixo) e percentual de abertura de fachada (PAF 20\%, 40\%, 60\% e 90\%), e foram analisados para três situações de iluminância mínima: 100 lux, 300 lux e 500 lux. Planilhas eletrônicas foram utilizadas para adequar os critérios de UDI e DAmax. Foram consideradas as métricas de DAmax para 100 lux, 300 lux e 500 lux, e três intervalos de UDI (100-2.000 lux, 300-3.000 lux e 500-5.000 lux), comparando os resultados convencionais com DAmax e UDI propostos. Os resultados demonstraram que o intervalo convencional de UDI e DAmax desconsideram ocorrências significativas de luz natural útil e uniformidade em situações de grande luminosidade. O estudo contribui ao propor intervalos de UDI e DAmax mais adequados para análises de desempenho luminoso nos trópicos.

Alice Ruck Drummond Dias Universidade Federal do Rio Grande do Norte
RN - Brasil

J uliana Portela Vilar Carvalho Universidade Federal do Rio Grande do Norte Natal - RN - Brasil

Viviane Diniz Hazboun Universidade Federal do Rio Grande do Norte Natal - RN - Brasil

Aldomar Pedrini Universidade Federal do Rio Grande do Norte Natal - RN - Brasil

Recebido em 24/11/17 Aceito em 26/02/18
Palavras-chave: Iluminação natural. Uniformidade. Simulação computacional dinâmica.

\section{Abstract}

This paper aims to discuss the dynamic metrics Maximum Daylight Autonomy (DAmax) and Useful Daylight Illuminance (UDI) in daylight performance analysi in a tropical climate. Due to the high luminosity in the tropics, the results of these metrics may not provide adequate indications of uniformity and daylight availability in the room. Dynamic simulations were performed in Daysim software of a multipurpose room with a shaded fenestration system. The models combined visible sky factor (VSF high, medium and low) and window-to-wall ratio (WWR $20 \%, 40 \%, 60 \%$ and $90 \%$ ), and were analyzed for three situations of minimum illuminance: 100 lux, 300 lux e 500 lux. Spreadsheets were used to customize the UDI and DAmax criteria. DAmax metrics for 100 lux, 300 lux, 500 lux, and three UDI intervals (100-2000 lux, 300-3.000 lux and 500-5.000 lux) were considered, comparing the conventional results with DAmax and UDI proposed by the spreadsheet. The results showed that conventional UDI and DAmax disregard significant occurrences of useful daylight in situations of high luminosity. The study contributes with proposed intervals of UDI and DAmax that showed more coherence in the analysis of luminous performance in the tropics.

Keywords: Daylighting. Uniformity. Dynamic computational simulation. 


\section{Introdução}

A aplicação das métricas Daylight Autonomy (DA ou Autonomia de Luz Natural Máxima) e Useful Daylight Illuminance (UDI ou Iluminância Natural Útil) pode resultar em avaliações de desempenho luminoso significativamente diferentes em condições de alta radiação solar externa, como em climas tropicais, levando a tomadas de decisões projetuais divergentes. Ambos os critérios foram desenvolvidos para condições de disponibilidade de luz natural externa inferior à dos trópicos, e seus limites são cada vez mais flexibilizados.

$\mathrm{O}$ artigo visa discutir a aplicabilidade e a coerência das métricas dinâmicas DAmax e UDI como indicativos de disponibilidade e uniformidade da luz, respectivamente, contribuindo para procedimentos adequados na análise da distribuição e aproveitamento da luz natural em cidades de clima tropical.

As análises partem do princípio de que o uso da luz natural em edificações de regiões tropicais pode ser reduzido devido ao excesso de luz, que pode gerar desconforto visual devido à ocorrência de contrastes e ofuscamento. O principal indicativo dessas ocorrências é a falta de uniformidade da luz, decorrente principalmente da incidência de radiação direta ou excesso de luz difusa no ambiente. Por isso, elementos de sombreamento nas aberturas são imprescindíveis para atenuar o excesso de luz, o que implica a redução do fator de céu visível (FCV), que, por sua vez, requer o aumento da abertura (ou adotar elementos de sombreamento com maior FCV) para atender aos limites mínimos de iluminância no plano de trabalho exigidos por norma.

\section{Referencial teórico}

O aproveitamento da luz natural no ambiente pode ser influenciado pelo desempenho do sistema de abertura e pelo critério de análise adotado. Para isso, é necessário considerar o impacto dos componentes dos sistemas de aberturas sombreadas e as métricas de avaliação no desempenho luminoso.

A literatura tanto internacional quanto nacional tem demonstrado a influência de variáveis como sistema de sombreamento, percentual de abertura na fachada (PAF) e fator de céu visível (FCV) de janela no desempenho luminoso (O’CONNOR et al., 1997; LEDER; PEREIRA; CLARO, 2008; CARVALHO, 2014; MORENO, 2015; DIAS, 2016).

Os dispositivos de sombreamento protegem a abertura da incidência de radiação solar excessiva, garantindo maior aproveitamento da luz natural por meio da distribuição uniforme no espaço, além de evitar ofuscamento e desconforto térmico (RUCK et al., 2010; SOUZA, 2004). O PAF corresponde à razão entre as áreas de abertura e de fachada (LAMBERTS et al., 2009), sendo referenciado em recomendações internacionais (O'CONNOR et al., 1997) e nos Requisitos Técnicos da Qualidade para o Nível de Eficiência Energética de Edifícios Comerciais, de Serviços e Públicos (RTQ-C) (INSTITUTO..., 2010a). O FCV refere-se à quantidade de céu visível da abertura em relação às obstruções do entorno e tem influência no conforto térmico (SOUZA et al., 2010; COLLISCHONN; FERREIRA, 2015; PAULA et al., 2016) e luminoso (O'CONNOR et al., 1997; CHATZIDIMITRIOU; YANNAS; 2004; LEDER, 2007; LEDER; PEREIRA; CLARO, 2008; CARVALHO, 2014; MORENO, 2015; CARVALHO et al., 2016; DIAS, 2016). Pode ser calculado por meio do software Apolux (CLARO, 2016) ou pelo mapeamento do percentual da área de céu visível da abóbada celeste obtida na máscara de sombra (CARVALHO, 2014), com o auxílio dos softwares Autocad (AUTODESK, 2013) e Solar Tool (MARSH, 2010).

A avaliação do desempenho pode ser feita por meio de diversos critérios, tais como Fator de Luz do Dia, Autonomia de Luz Natural, Autonomia de Luz Natural Contínua, Autonomia de Luz Natural Máxima, Iluminância Natural Útil, Percentual de Saturação de Luz Natural e Exposição Anual da Luz Natural. Os critérios mais recorrentes na literatura são DA (REINHART, 2001; CINTRA, 2011; MARCHIS et al., 2011; ALBUQUERQUE; AMORIM, 2012; GONZÁLEZ; FIORITO, 2015; CIRÍACO, 2016; DIAS, 2016) e UDI (NABIL; MARDALJEVIC, 2005, 2006; MARDALJEVIC et al., 2011; CARVALHO, 2014; GONZÁLEZ; FIORITO, 2015; MORENO, 2015; CIRÍACO, 2016). O DAmax é menos recorrente na literatura, porém se destaca para análises de uniformidade da luz natural em situações de contrastes em locais com grande luminosidade, como é o caso de climas tropicais.

O DA utiliza a iluminância do plano de trabalho como um indicador de que há luz natural suficiente para o desempenho da tarefa apenas com a luz natural (REINHART; MARDALJEVIC; ROGERS, 2006). Esse conceito foi redefinido como o percentual de horas ao ano em que há o atendimento do nível mínimo de iluminância requerido apenas com o uso da luz natural (REINHART; 
WALKENHORST, $2001^{1}$ apud REINHART; MARDALJEVIC; ROGERS, 2006). Essa definição foi aperfeiçoada para modelos de comportamento de usuários com persianas de acionamento manual, predizendo sua movimentação durante o horário de ocupação da edificação ao longo do ano (REINHART; BOURGEOIS; DUBROUS, 2003; REINHART; ANDERSEN, 20062 apud REINHART; MARDALJEVIC; ROGERS, 2006).

O DAmax refere-se ao percentual de horas ao ano em que há incidência de luz direta ou em excesso (REINHART, 2010b) e é definido para ocorrências superiores à proporção de 1/10 em relação ao nível de iluminância. O nível superior detecta a ocorrência de luz solar direta ou outras condições de potencial ofuscamento, indicando a presença de contrastes (REINHART, 2010b) e falta de uniformidade em regiões de alta luminosidade (MARQUES, 2012). Entretanto, os dados gerados por ferramentas computacionais, como o Daysim, referem-se ao nível mínimo requerido para a iluminância de projeto, não estabelecendo uma relação entre os níveis mínimos e máximos encontrados no ambiente (DIAS, 2016). A proporção de 1/10 em relação à iluminância exigida de projeto (REINHART; MARDALJEVIC; ROGERS, 2006) não considera diferentes contextos climáticos, como o caso de regiões tropicais. Destaca-se que a abordagem desse critério não é clara no tutorial da ferramenta (REINHART, 2010b), o que pode ocasionar entendimento incorreto por parte dos usuários do programa ou pesquisadores da área.

O UDI refere-se ao percentual de horas ao ano em que ocorrem níveis de iluminância para os intervalos abaixo de 100 lux, entre 100 lux e 2.000 lux, e acima de 2.000 lux (REINHART; MARDALJEVIC; ROGERS, 2006). O intervalo superior é significante para detectar as horas em que o excesso de luz pode levar ao desconforto visual ou térmico (REINHART, 2010b). O desempenho da tarefa visual requer um intervalo de iluminância entre 100 lux e 3.000 lux, porém níveis acima desse intervalo podem ser benéficos para a saúde, sugerindo que ocorrências de UDI em excesso de forma moderada podem ser desejáveis e não devem ser totalmente descartadas (MARDALJEVIC et al., 2011). O critério de UDI fornece uma visão mais ampla da dinâmica espaço-temporal da luz natural, oferecendo indicações de desconforto baseadas nos ganhos solares (NABIL; MARDALJEVIC, 2006). Em condições de alta luminosidade, é preciso adaptar os níveis de iluminância ou intervalos

IREINHART, C. F.; WALKENHORST, O. Dynamic RADIANCE-Based Daylight Simulations for a Fullscale Test Office With Outer Venetian Blinds. Energy \& Buildings, v. 33, n. 7, p. 683-6971, 2001. prescritos nos parâmetros de avaliação da luz natural para as condições locais de iluminação (CARVALHO, 2014; MORENO, 2015; DIAS, 2016). A literatura internacional aponta limitações quanto ao critério de avaliação do UDI em relação à necessidade de adaptação dos níveis mínimos e máximos (MARDALJEVIC et al., 2011), e o programa Daysim (REINHART, 2010a) apresenta limitações na determinação quantitativa dessa métrica. Dias (2016) destaca a necessidade de ter uma métrica de avaliação que considere a relação entre os níveis de iluminância mínimos e máximos obtidos no ambiente para avaliação da uniformidade.

O critério de uniformidade é descrito nas normas brasileiras de iluminação para interiores (ABNT, 1992) e ambientes de trabalho (ABNT, 2013). A norma para análise de iluminação natural em ambientes de trabalho (ABNT, 2013) estabelece que a uniformidade da iluminância de tarefa não pode ser inferior a 0,7 , ao passo que a uniformidade da iluminância de entorno imediato não pode ser menor que 0,5. Já a norma para iluminação de interiores (ABNT, 1992), revogada com a publicação da NBR 8995-1 (ABNT, 2013), estabelece uma relação de $1 / 10$ entre as iluminâncias mínima e máxima encontradas no ambiente para o campo de trabalho.

De acordo com as normas de iluminação natural, cada atividade a ser desempenhada prevê um uso diferente e, portanto, níveis mínimos de iluminância específicos para a execução da tarefa visual. Dessa forma, é necessário adaptar o nível de iluminância mínimo requerido de acordo com a iluminância prescrita por norma.

\section{Método}

O método consiste na análise comparativa de diferentes intervalos dos critérios DAmax e UDI para a avaliação da distribuição e aproveitamento da luz natural em salas multiúso localizadas em climas tropicais. O DAmax é avaliado para as situações de 100 lux, 300 lux e 500 lux, conforme gerado pelo software (DAmax convencional), e para a relação de 1/10 entre as iluminâncias mínima e máxima encontradas no ambiente (DAmax proposto). O UDI varia entre os intervalos de 100-2.000 lux (UDI convencional), 300-3.000 lux e 500-5.000 lux, e UDI proposto, que adota a relação de $1 / 10$ para a definição do UDI excessivo. Foram escolhidos os níveis de iluminância de 100 lux, 300 lux e 500 lux para dar maior representatividade ao estudo,

2REINHART, C. F.; ANDERSEN, M. Development and Validation of a Radiance Model For a Translucent Panel. Energy and Buildings, v. 38, n. 7, p. 890-904, 2006 
observando casos com diferentes parâmetros de iluminância requerida, seja na função de edifício residencial, como de outras tipologias. O nível mínimo de iluminância adotado de 100 lux corresponde ao valor mínimo para uma iluminância natural útil, segundo Mardaljevic et al. (2011). O limite de 300 lux é recomendado pela norma ISO/CIE 8995-1 para ambientes como salas de multiúso, salas de aula, salas de leitura, salas de arte e artesanato, salas de esportes, entre outros, enquanto o atendimento de 500 lux supre a luminosidade necessária para as atividades de acabamento e decoração, salas para atendimento médico, laboratórios, oficinas, cabeleireiro, costura, escritório, salas de reunião e conferência, área de leitura de bibliotecas, entre outros.

Os procedimentos do método foram divididos em três etapas principais: definição dos modelos, simulação computacional e análise dos dados (Figura 1).

\section{Definição dos modelos}

Os modelos simulados foram definidos por meio de combinações entre dimensão da abertura e FCV, visto que esses critérios têm grande influência na disponibilidade de luz natural no ambiente (O’CONNOR et al., 1997). A dimensão da abertura é representada pelo PAF, sendo estabelecidas variações de $20 \%$, 40\%, 60\% e $90 \%$. Os percentuais foram baseados em Carvalho (2014) e Moreno (2015), e calculados conforme o RTQ-C (INSTITUTO..., 2010a). O FCV foi classificado em pequeno (3\%), médio (30\%) e grande (50\%) a partir da quantificação da obstrução da abertura por meio de proteção solar (Figura 2). Esses percentuais de céu visível foram definidos para representar três situações: obstrução praticamente total da abertura, quando apenas 3\% da área de céu é visível; situação intermediária, na qual aproximadamente metade da abobora celeste é visível (30\%); e situação com menor obstrução possível do céu (porém garantindo a obstrução da radiação direta), que para a carta solar em questão obteve o valor de $50 \%$ de FCV.

Figura 1 - Diagrama geral do método

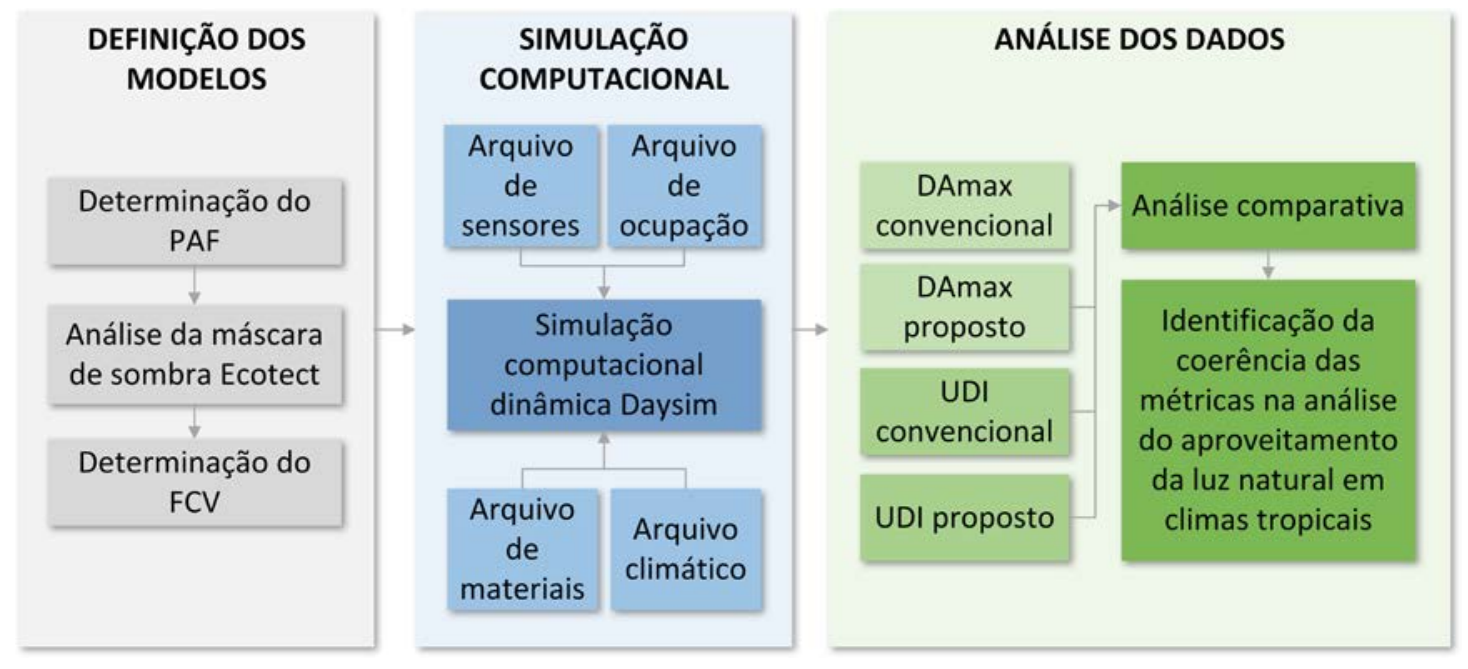

Figura 2 - Máscaras de sombra dos modelos

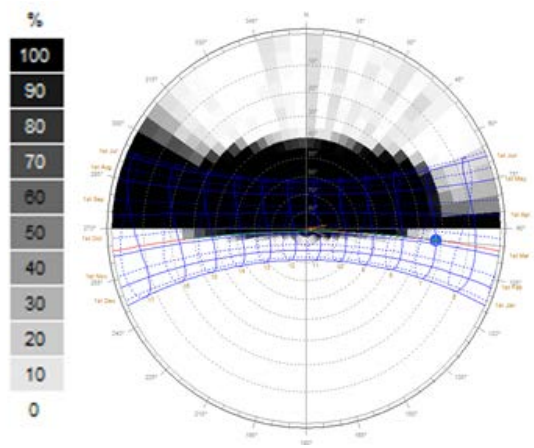

(a) FCV grande (50\%)

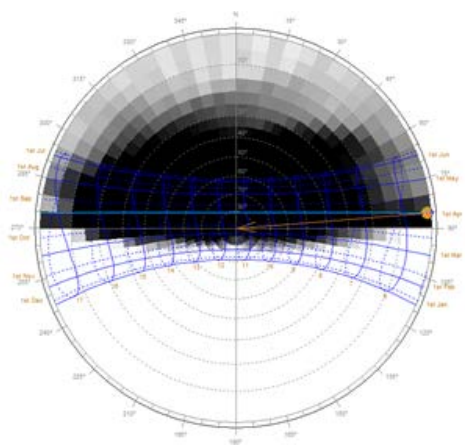

(b) FCV médio (30\%)

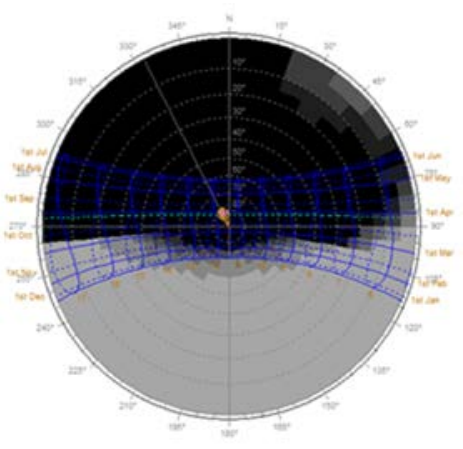

(c) FCV pequeno (3\%)

Fonte: Dias (2016). 
Foram simulados 12 modelos a partir da combinação dessas variáveis (Figura 3) e considerados três níveis mínimos de iluminância (100 lux, 300 lux e 500 lux), gerando ao final 36 casos analisados. Os limites mínimos de UDI foram estabelecidos para abranger diferentes usos do ambiente.

Os modelos foram determinados a partir do critério de sombreamento total da abertura (bloqueio de $100 \%$ da radiação solar direta) das $8 \mathrm{~h}$ às $16 \mathrm{~h}$ e favorecimento da desobstrução da abóboda celeste para o aproveitamento da luz difusa e contato com o meio externo. Os PAF e FCV definidos visam ao aumento gradativo da incidência de luz natural no ambiente conforme a variação desses parâmetros. O sistema de sombreamento teve suas dimensões ajustadas conforme variação do tamanho de abertura para a obtenção do padrão de sombreamento estabelecido (sombreamento de 100\% da radiação direta de 8h-16h).

A quantificação do FCV se baseou no método proposto por Carvalho (2014) por meio das etapas de:

(a) modelagem;

(b) obtenção da máscara de sombra;

(c) mapeamento das áreas equivalentes a cada um dos percentuais de sombreamento; e

(d) cálculo do FCV, por meio dos softwares Revit, Ecotect, AutoCad e Excel (Figura 4).

Os modelos consistem em um ambiente térreo multiúso com dimensões de 5,00 m x 5,00 m e pédireito de 3,00 m (Figura 5). A abertura é voltada para a fachada norte para favorecer um maior aproveitamento da luz natural difusa. Foram estabelecidas as refletâncias do teto, parede e piso de 0,90, 0,90 e 0,70, respectivamente, e uso de vidro claro com transmissividade de luz visível de 0,90.
Os modelos foram avaliados quanto ao conforto térmico em análises anteriores realizadas por meio de simulação computacional no programa Design Builder. A análise constatou desempenho térmico otimizado dos modelos, através do método de conforto adaptativo indicado pela Standard 55 (2010) com base no modelo de De Dear e Brager (2002), considerando o efeito do movimento de ar para classificação das ocorrências das faixas de conforto, conforto no caso da existência de movimentação do ar e desconforto ao calor e ao frio. Os resultados apontam $0 \%$ de desconforto ao calor em praticamente todos os modelos, com exceção de alguns casos com PAF de $60 \%$ e $90 \%$, em que ocorreu a máxima de $1 \%$ de desconforto ao calor. Conclui-se que os modelos estão em consonância com as recomendações bioclimáticas e requisitos de desempenho térmico para o clima quente úmido, visando a condições adequadas aos usuários. Todos os modelos obtiveram classificação nível A de eficiência energética na etiqueta PBE Edifica.

\section{Simulação computacional}

O processo de simulação computacional no Daysim consiste nas etapas:

(a) modelagem tridimensional no software Sketchup;

(b) definição da malha de sensores com 25 pontos (Figura 6) conforme a NBR 15215-4 (ABNT, 2005, p. 6-7);

(c) inserção dos dados de entrada relativos ao arquivo climático (extensão .*EPW) da cidade de Natal, RN, modelo tridimensional (extensão *3DS), arquivo de sensores (extensão .*PTS) e de ocupação (extensão .*CSV); e

(d) configuração das propriedades ópticas dos materiais.

Figura 3 - Combinações de PAF e FCV dos modelos

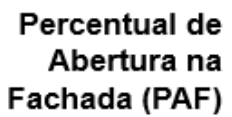

Fator de Céu Visivel (FCV)

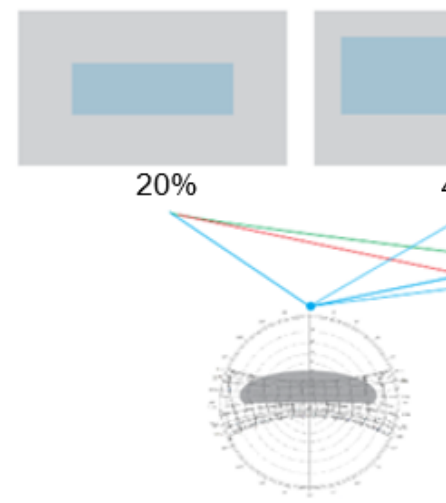

Grande (50\%)
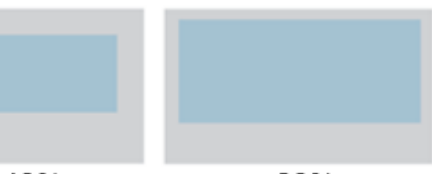
$60 \%$

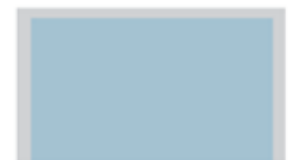
$90 \%$

Fonte: Dias (2016). 
Figura 4 - Etapas para determinação de FCV dos modelos

\section{FATOR DE CÉU VISÍVEL (FCV)}

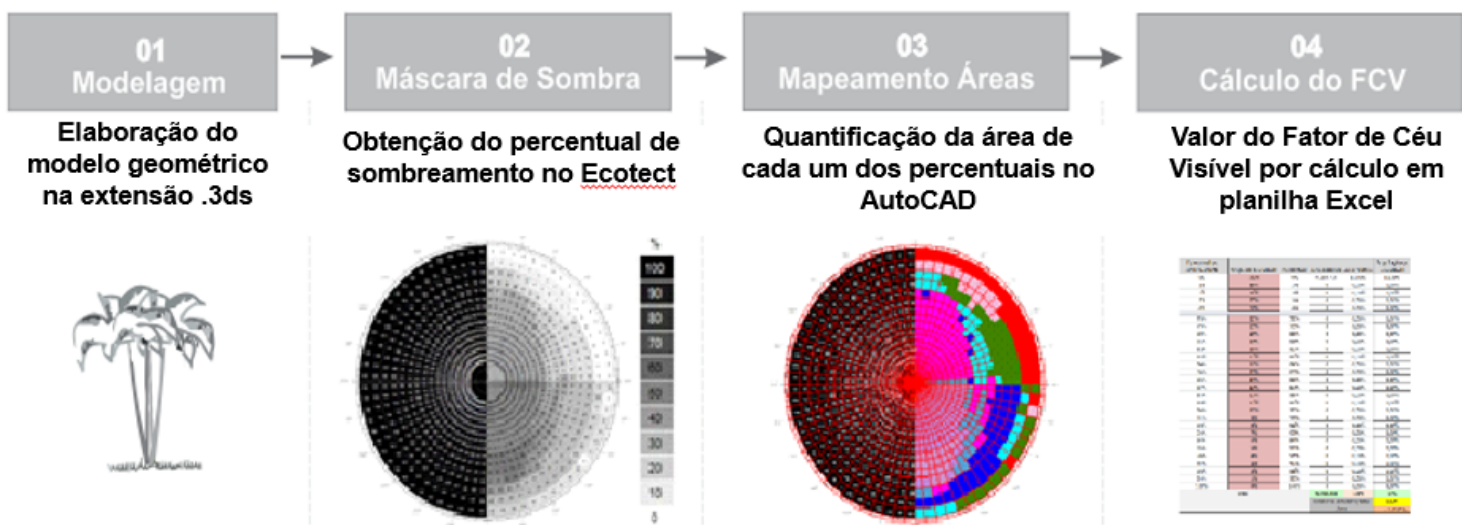

Fonte: adaptada de Carvalho (2014).

Figura 5 - Planta baixa, corte e vista interna do ambiente analisado (PAF 40\%)

Fachada Sul

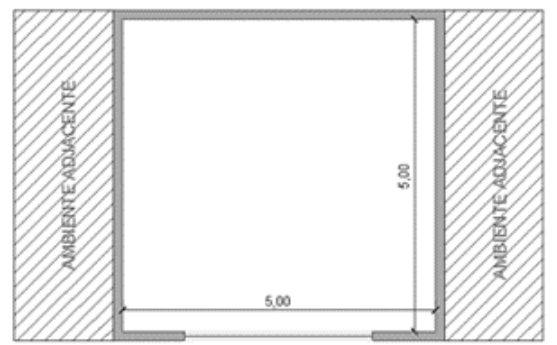

Fachada Norte

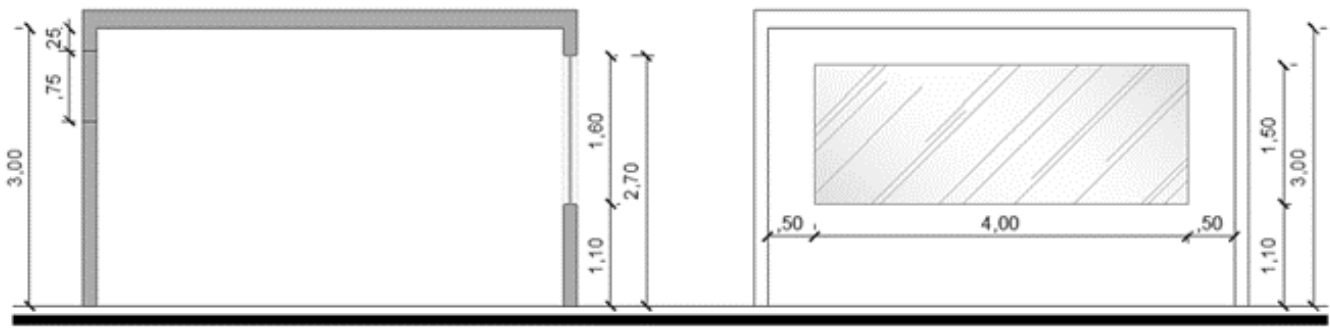

CORTE

VISTA INTERNA

Fonte: Dias (2016).

Figura 6 - Mapa de sensores dos modelos

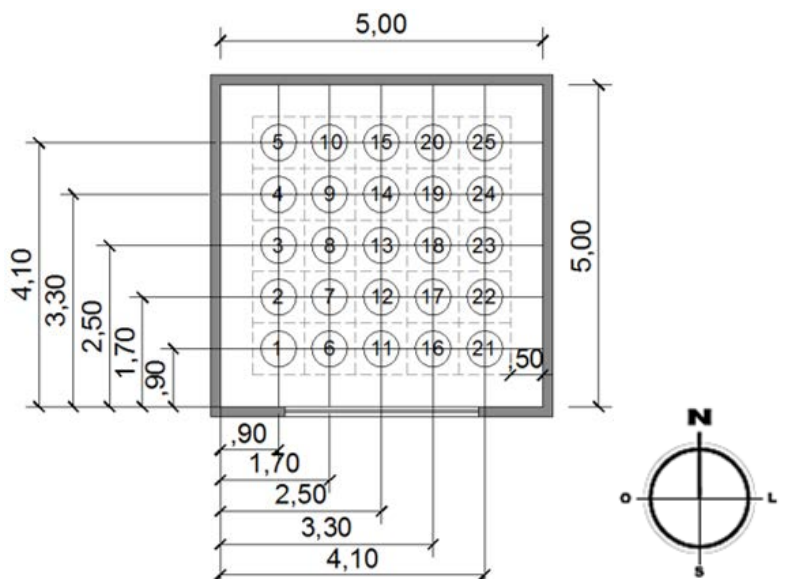


Os modelos foram simulados para a cidade de Natal (RORIZ, 2009) para representar uma localidade de clima tropical com altos índices de radiação solar (Figura 7). Foi utilizado o arquivo climático do ano de 2009 (RORIZ, 2009), devido à maior representatividade deste em relação ao arquivo de 1954 quanto aos dados de iluminação natural e radiação solar (2014) em Natal.

Os dados do arquivo de 2009 foram coletados a partir dos anos 2000, sendo medidos pelas estações automáticas do INMET. Os arquivos originais continham oito variáveis de interesse: temperatura do ar, umidade relativa, temperatura do ponto de orvalho, pressão atmosférica, velocidade e direção do vento, pluviosidade e irradiância global sobre o plano horizontal. O formato definido para os arquivos foi o .*EPW, presente no programa Energy Plus (DOE, 2012), e as variáveis calculadas foram:

“(a) irradiâncias - extraterrestre horizontal, extraterrestre normal, difusa horizontal e direta normal. Método Muneer (1997³ apud RORIZ, 2012)

(b) luminância no zênite e iluminâncias global horizontal, difusa horizontal e direta normal. Método Perez et al. $\left(1990^{4}\right.$ apud RORIZ, 2012)”.

As outras variáveis foram calculadas por meio do Weather-Converter. O ano climático de referência foi identificado por meio do TMY (Tipical Metereological Year), que consiste na exclusão dos anos mais quentes e mais frios para a identificação do ano típico local (RORIZ, 2012).

\section{Análise dos dados}

\section{DAmax}

Os valores de DAmax, fornecidos automaticamente pelo Daysim, foram analisados para níveis de iluminância de 100 lux, 300 lux e 500 lux. A ocorrência de relações entre as iluminâncias mínima e máxima encontradas no ambiente superiores a 1/10, conforme orienta a ABNT (ABNT, 1992) para avaliação da uniformidade, foi calculada posteriormente por meio de planilha eletrônica no Excel (DAmax proposto). Os resultados de DAmax para 100 lux, 300 lux e 500 lux e do DAmax proposto pelos pesquisadores foram comparados com o objetivo de avaliar o comportamento desses indicadores de uniformidade e as discrepâncias encontradas nos resultados, à medida que a disponibilidade de luz aumenta no ambiente. A Figura 8 apresenta os limites que cada métrica (DAmax 100 lux, 300 lux e 500 lux e DAmax proposto) considerando os valores da faixa em amarelo (Figura 8) como percentual de ocorrência anual do DAmax, o que indica falta de uniformidade da luz natural, que pode vir a ocasionar ofuscamento.

Os resultados de cada modelo são apresentados por meio de gráficos percentuais com indicação das ocorrências de DAmax para 100 lux, 300 lux e 500 lux e do DAmax proposto. Esses resultados são apresentados para o recorte da fileira central de sensores dos modelos, representados pelas profundidades de 0,90 m, 1,30 m, 2,10 m, 3,30 m e 4,10 m em relação à abertura, conforme exemplo da Figura 9.

Figura 7 - Radiação solar direta e difusa em Natal, RN

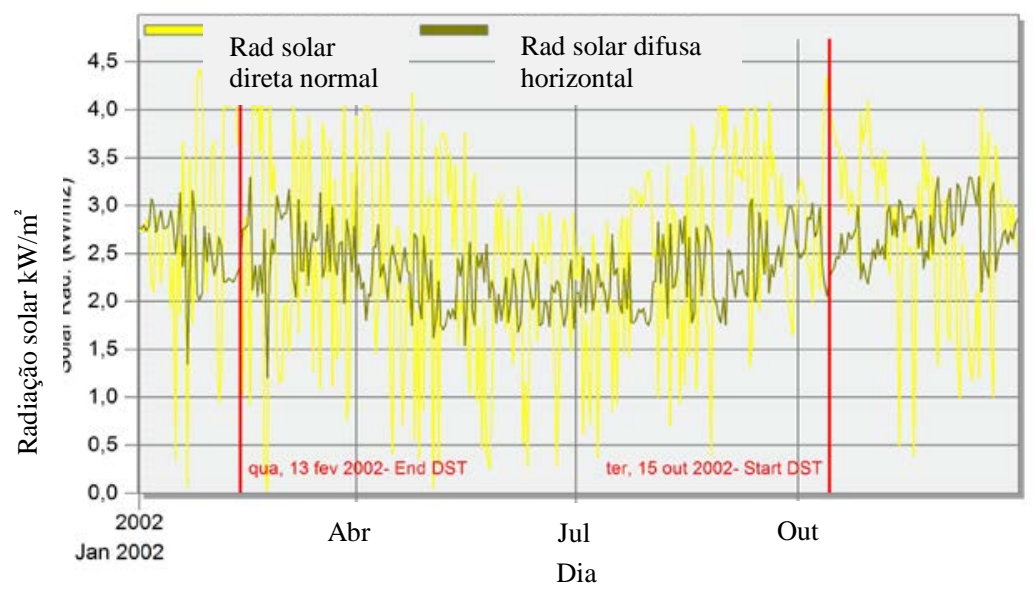

Fonte: adaptado de DesignBuilder (2010) com base no arquivo climático de 2009 (RORIZ, 2009).

3MUNEER, T. Solar Radiation and Daylight Models for the Energy Efficient Design of Buildings. Oxford: Elsevier Butterworth-Heinemann, 1997.
4PEREZ, R. et al. Modelling Daylight Availability and Irradiance Components From Direct and Global Irradiance. Solar Energy, v. 44 , p. $271-289,1990$ 
Figura 8 - Intervalo das métricas DAmax para 100 lux, 300 lux e 500 lux e DAmax proposto
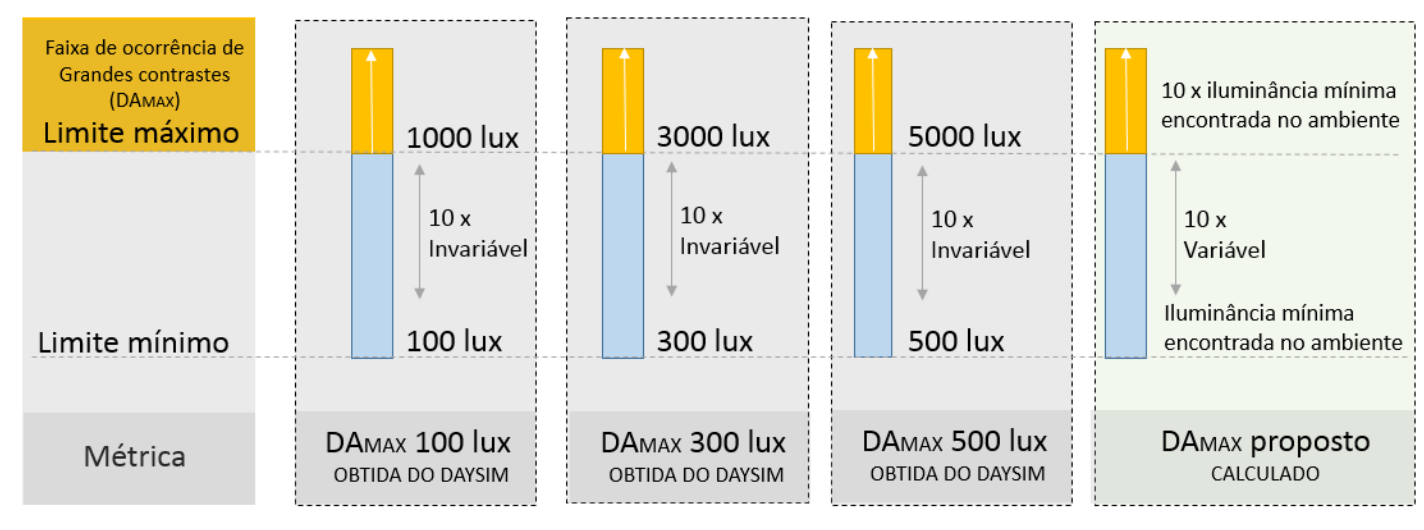

Figura 9 - Saída gráfica dos resultados de DAmax para 100 lux, 300 lux e 500 lux e do DAmax proposto

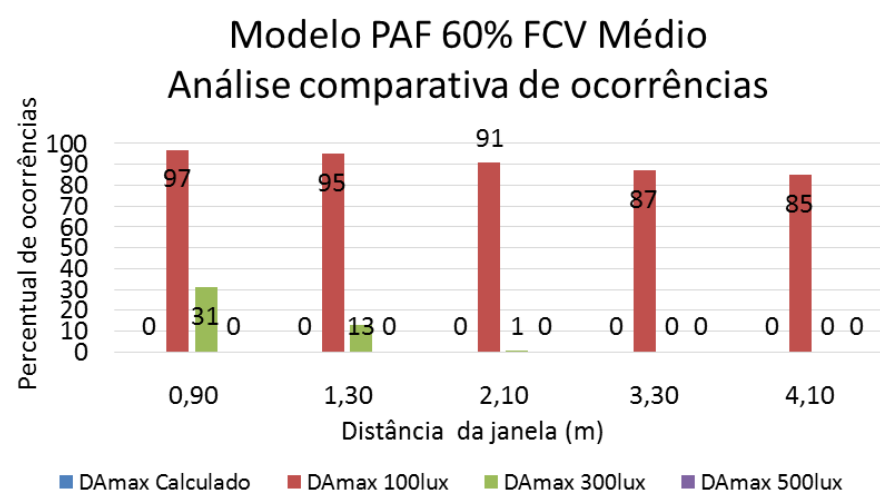

\section{UDI}

Os resultados de UDI foram tratados para limites convencionais adotados pela literatura de UDI insuficiente, UDI autônomo e UDI excessivo, cujos valores correspondem aos intervalos de 100-2.000 lux, 300-3.000 lux e 500-5.000 lux. Um UDI proposto foi definido para situações de grande luminosidade, cujo limite inferior é composto da iluminância mínima exigida por norma (caracterizando a disponibilidade da luz - que se relaciona com variável critério DA) e do limite superior, por valores que excedem a relação de 1/10 entre iluminâncias no ambiente em dado momento (caracterizando a uniformidade da luz natural - que se relaciona com variável critério DAmax proposto). A faixa considerada dentro do intervalo é denominada de UDI autônomo (representada pela faixa azul na Figura 10), cujas ocorrências refletem o atendimento aos critérios de disponibilidade e uniformidade da luz natural. O UDI proposto é variável em função do atendimento dos índices de iluminância, diferentemente do modo convencional, baseado em uma faixa de iluminância fixa (Figura 10).

Os valores de UDI proposto foram comparados com os UDI convencionais, avaliando-se o comportamento das ocorrências à medida que se varia a disponibilidade de luz nos modelos. A saída gráfica dos resultados indica a ocorrência de UDI para cada situação (100 lux, 300 lux e 500 lux) e os valores complementares de DA e DAmax, para dar suporte às análises (Figura 11). Foi considerado o recorte representativo da fileira central de sensores com profundidades de 0,90 m, 1,30 m, 2,10 m, 3,30 m e 4,10 m em relação à abertura.

\section{Resultados e discussões}

\section{DAmax}

As simulações demonstram que a métrica DAmax obtida automaticamente pelo Daysim varia em função do limite mínimo estabelecido para iluminância de projeto (100-300-500 lux), não sendo vinculada à relação entre iluminância mínima e máxima ocorrida no ambiente em dado momento. Assim, para um mesmo modelo simulado foram obtidos diferentes valores de DAmax. Os resultados, em geral, revelaram discrepâncias substanciais entre as métricas, com diferenças de até $97 \%$ entre as indicações de ocorrência de falta de uniformidade fornecidas pelo DAmax obtido pelo Daysim e o DAmax calculado. 
Figura 10 - Intervalo das métricas UDI analisadas
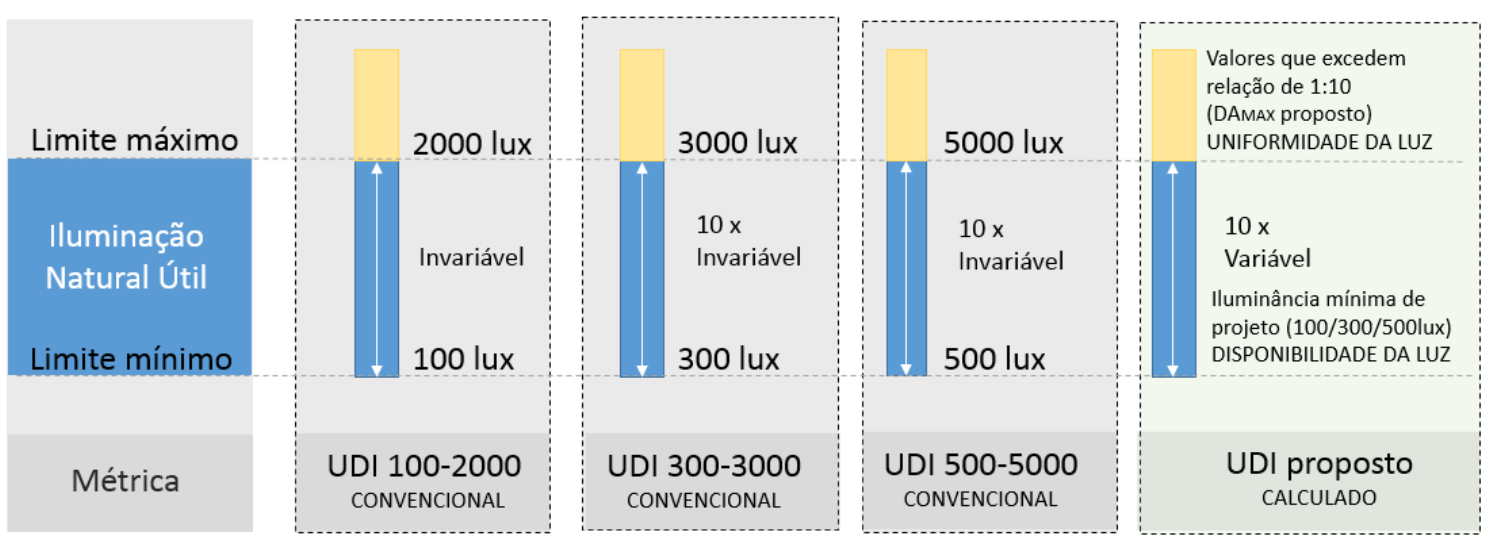

Figura 11 - Saída gráfica dos resultados de UDI para situação de 100 lux, 300 lux e 500 lux, complementados pelos dados de DA e DAmax MÉTODO CONVENCIONAL - PAF 60\% FCV Médio
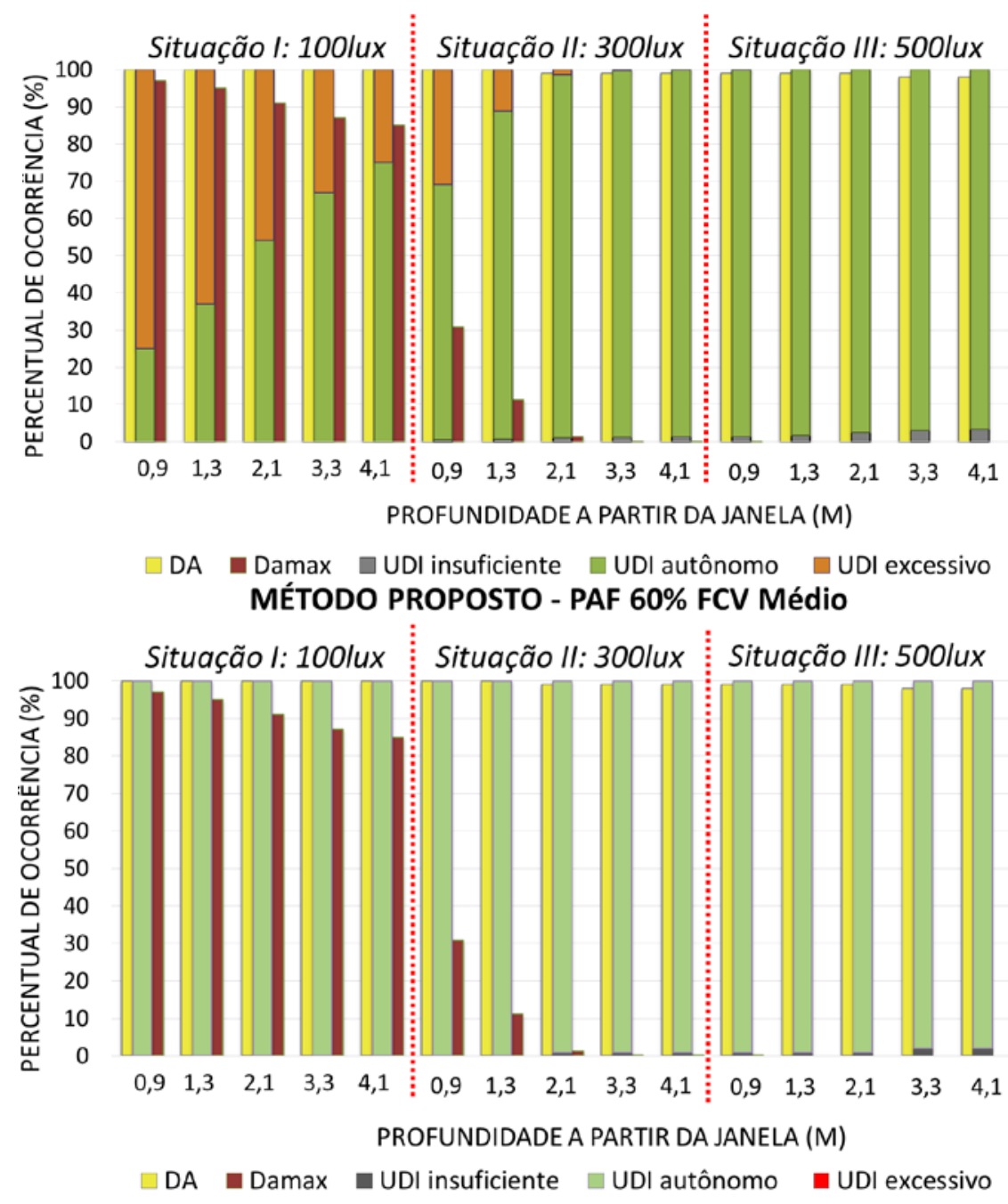
Nos casos em que foi preestabelecido o critério mínimo de 500 lux, o DAmax apontou grande ocorrência de uniformidade, da mesma forma que o DAmax calculado. Para a situação de 100 lux, o DAmax resulta em pequena indicação de uniformidade, por ultrapassar o limite superior de 1.000 lux (10 vezes o limite inferior de 100 lux), sendo nesse caso encontradas as maiores divergências. Foram encontrados valores de $0 \%$ de DAmax para 500 lux (que indica 100\% de uniformidade) em todos os modelos, com exceção dos modelos com PAF 90\% e FCV médio e grande, em que foi encontrado 1\% de DAmax (que indica 99\% de uniformidade). No DAmax para 100 lux são obtidos valores de até $98 \%$, o que indica $2 \%$ de uniformidade (Figuras 12, 13 e 14). Isso ocorre porque o cálculo do DAmax considera uniformes valores de iluminância até 5.000 lux, quando o critério mínimo é 500 lux, e restringe essa faixa de aceitação para o limite de 1.000 lux quando o critério mínimo de iluminância é de 100 lux, indicando significativamente menos uniformidade neste último caso devido aos altos índices de iluminância obtidos em Natal. As ocorrências de UDI dos modelos (como dado complementar à análise do DAmax) demonstram que predominam níveis de luz natural difusa superiores a 1.000 lux (Figura 16) mesmo quando a abertura é pequena com pouca fração de céu visível (PAF 20\% e FCV pequeno - 3\%). Os valores máximos são superiores a 2.000 lux em mais de $80 \%$ das ocorrências anuais nos modelos de PAF 90\% e FCV grande (Figura 14), com iluminância difusa de até 13.290 lux.

Os modelos com FCV pequeno e PAF de 20\%, 40\% e $60 \%$ (Figura 12) são os únicos casos em que todos os valores encontrados de DAmax (DAmax para 100 lux, 300 lux, 500 lux e DAmax calculado) são iguais, visto que existe uma pequena área de abertura para entrada de luz natural (pelo pequeno valor de FCV e PAF), acarretando valores de iluminância menores que 1.000 lux. Quando o PAF é de $90 \%$, mesmo com o FCV pequeno, a métrica DAmax para 100 lux chega a indicar 44\% de ocorrência anual de falta de uniformidade (Figura 12), enquanto as demais métricas indicam $100 \%$ de uniformidade (0\% de DAmax). Essa discrepância entre DAmax para 100 lux e os demais DAmax aumenta gradativamente à medida que o nível de luminosidade aumenta nos modelos, chegando a 98\%, conforme supracitado, no modelo com PAF 90\% e FCV grande (Figura 14).

\section{Figura 12 - Valores de DAmax dos modelos com FCV pequeno}

Modelo PAF 20\% FCV Pequeno

Análise comparativa de ocorrências

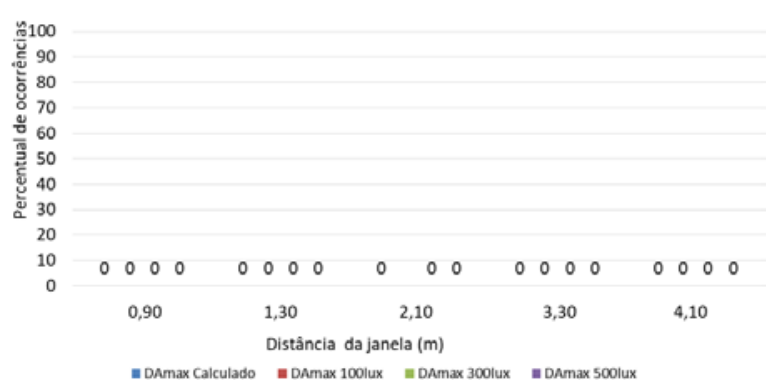

Modelo PAF 60\% FCV Pequeno Análise comparativa de ocorrências

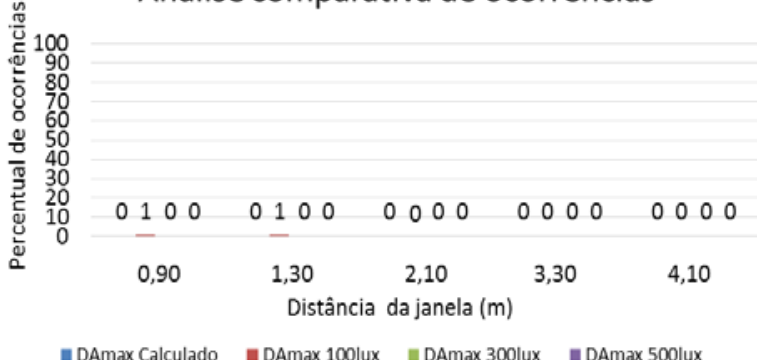

Modelo PAF 40\% FCV Pequeno Análise comparativa de ocorrências

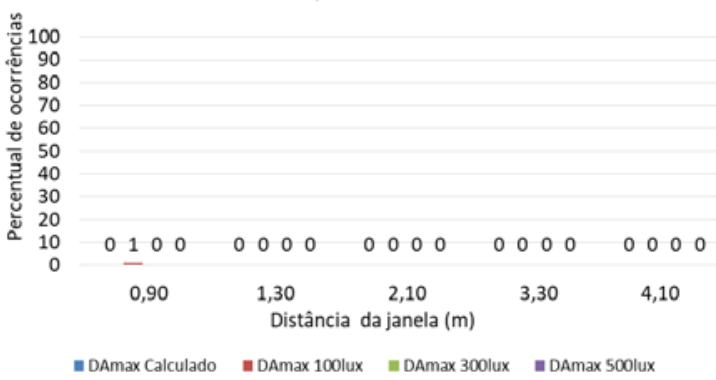

Modelo PAF 90\% FCV Pequeno Análise comparativa de ocorrências

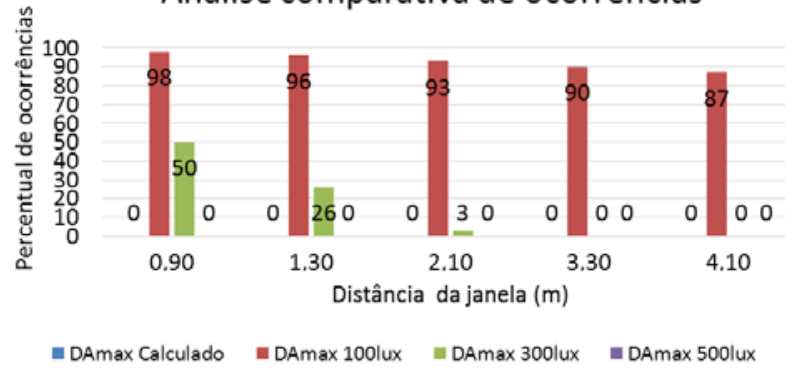


Figura 13 - DAmax dos modelos com FCV médio

Modelo PAF 20\% FCV Médio

Análise comparativa de ocorrências

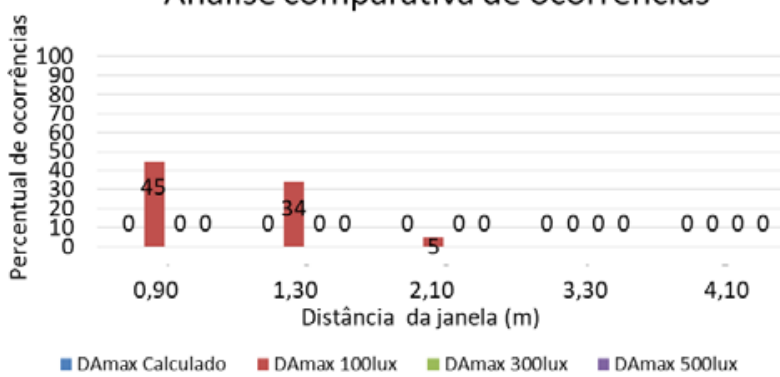

Modelo PAF 60\% FCV Médio

Análise comparativa de ocorrências

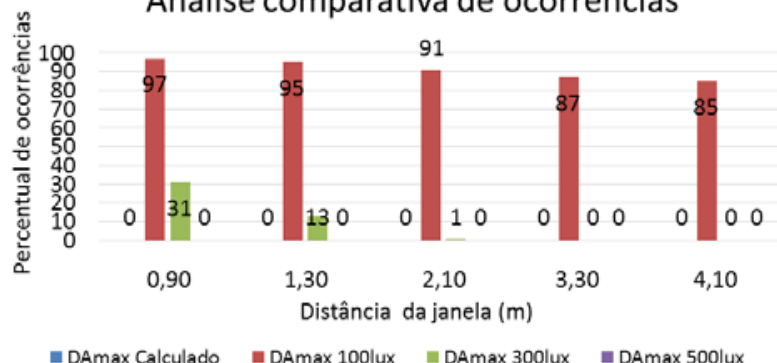

Figura 14 - DAmax dos modelos com FCV grande

Modelo PAF 20\% FCV Grande Análise comparativa de ocorrências

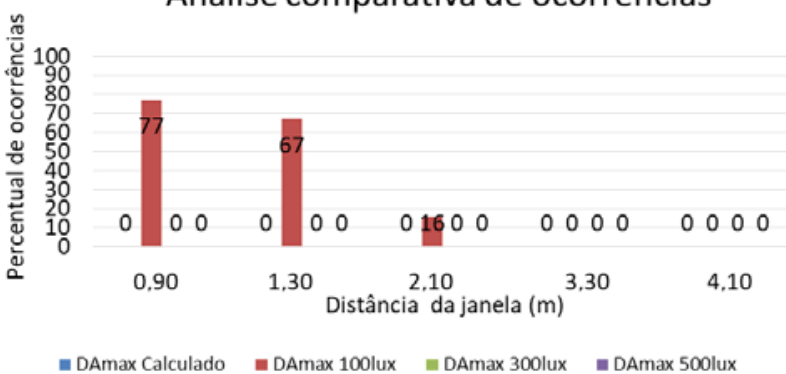

Modelo PAF 60\% FCV Grande Análise comparativa de ocorrências

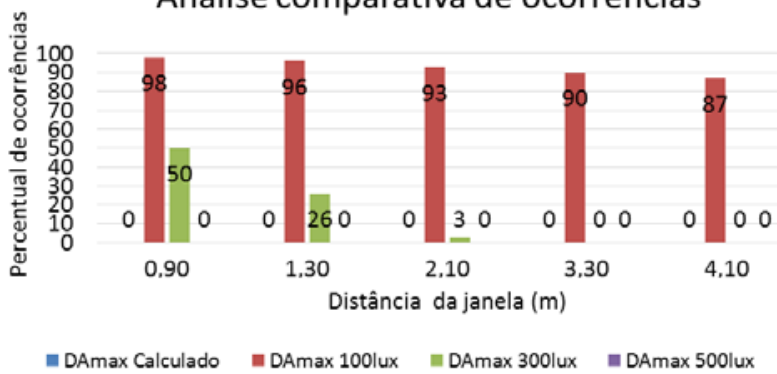

A Tabela 1 sintetiza os resultados de convergência de DAmax obtidos nas Figuras 12, 13 e 14, observando-se a divergência da métrica DAmax para 100 lux com as demais nos casos de PAF de $20 \%$ e $40 \%$, e do DAmax para 100 lux e 300 lux nos PAF de $60 \%$ e $90 \%$.
Modelo PAF 40\% FCV Médio Análise comparativa de ocorrências

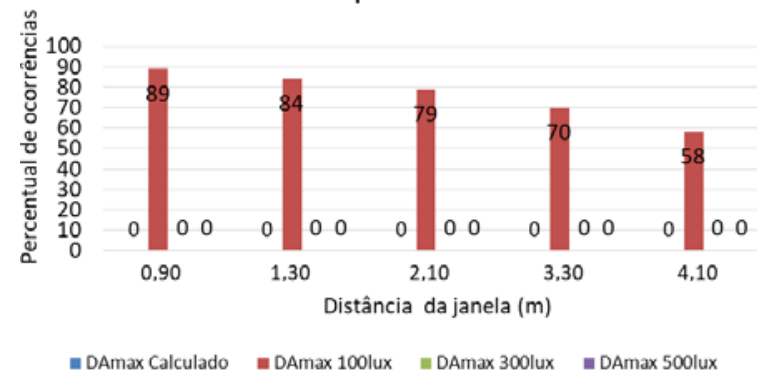

Modelo PAF 90\% FCV Médio Análise comparativa de ocorrências

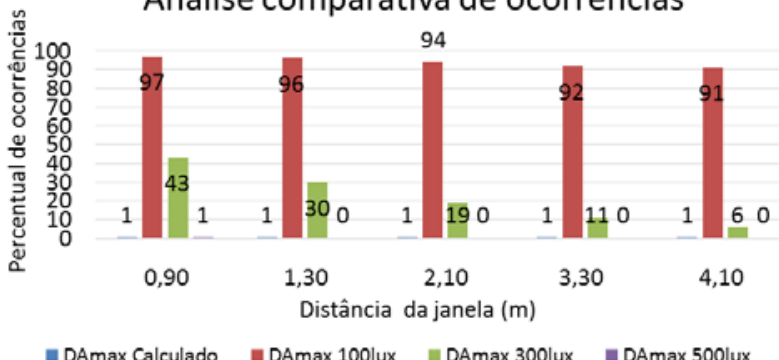

a DAmax Calculado =DAmax 100lux DAmax 300lux $=$ DAmax 500lux

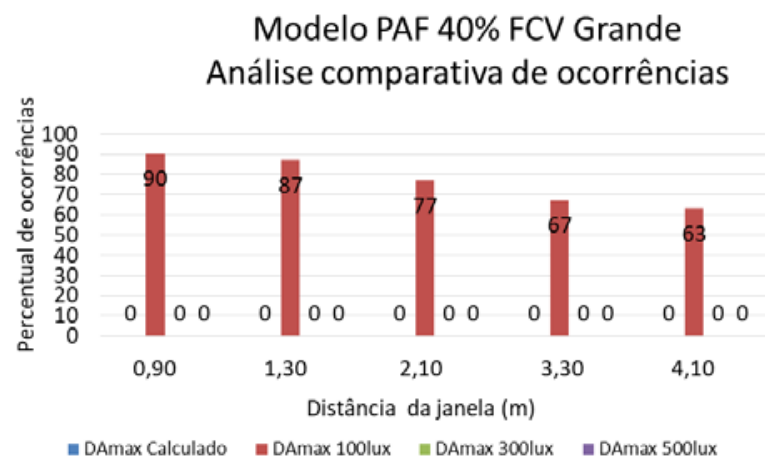

Modelo PAF 90\% FCV Grande Análise comparativa de ocorrências

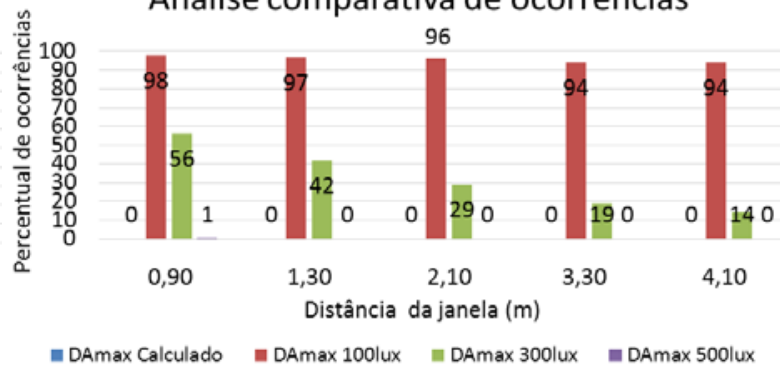

Os dados brutos de iluminância fornecidos pelo Daysim (extensão .*ill) do modelo PAF 90\% FCV grande (de maior disponibilidade de luz natural) demonstram que a relação entre as iluminâncias mínima e máxima encontradas nos sensores do ambiente é de 1:1,5 em sua maioria, com variação 
máxima de 1:3 (Figura 15 - relação de uniformidade em azul), valor consideravelmente abaixo da proporção de 1:10, conforme orienta a norma brasileira. Esses dados evidenciam que não existem grandes contrastes, uma vez que os modelos não possuem entrada de radiação direta.

Assim, considerando a forma de cálculo de DAmax obtido pelo Daysim, uma situação hipotética em que todas as iluminâncias anuais do ambiente no horário de ocupação variam entre 6.000 e 6.050 lux (relação entre iluminâncias mínima e máxima de aproximadamente 1:1), seria obtido DAmax para 100-300-500 lux de 100\% (uniformidade nula, indicando altos contrastes). Isso se demonstra incompatível para avaliação da uniformidade de ambientes em locais de alta luminosidade, que fazem uso de luz natural difusa abundante. Desse modo, a avaliação constata maior coerência no cálculo de uniformidade a partir do processamento de dados em planilha do Excel, considerando o limite de DAmax através da proporção de 1/10 em relação à iluminância mínima encontrada no ambiente a cada momento (DAmax proposto).

Tabela 1 - Indicação da ocorrência de DAmax = ou > 0 dos modelos - Comparativo de convergência da métrica DAmax

\begin{tabular}{|c|c|c|c|c|c|c|c|c|c|c|}
\hline \multirow{2}{*}{ MÉTRICA } & \multicolumn{10}{|c|}{ MODELOS } \\
\hline & 20peq & 20med & 20 gra & 40peq & 40med & 40gra & 60peq & \begin{tabular}{|l|l|}
$60 \mathrm{med}$ & 60 gra \\
\end{tabular} & \begin{tabular}{|l|l|} 
90peq & 90med \\
\end{tabular} & 90gra \\
\hline $\begin{array}{l}\text { DAmax } 100 \\
\text { lux }\end{array}$ & & & & & & & & & & \\
\hline $\begin{array}{l}\text { DAmax } 300 \\
\text { lux }\end{array}$ & & & & & & & & & & \\
\hline $\begin{array}{l}\text { DAmax } 500 \\
\text { lux }\end{array}$ & & & & & & & & & & \\
\hline $\begin{array}{l}\text { DAmax } \\
\text { Calculada }\end{array}$ & & & & & & & & & & \\
\hline
\end{tabular}

Nota: Legenda:

Ocorrência de DAmax $=0$ (uniformidade); e

Ocorrência de DAmax $>1 \%$ (ocorrência fora da faixa de uniformidade).

Figura 15 - Valores de iluminância e relação de uniformidade

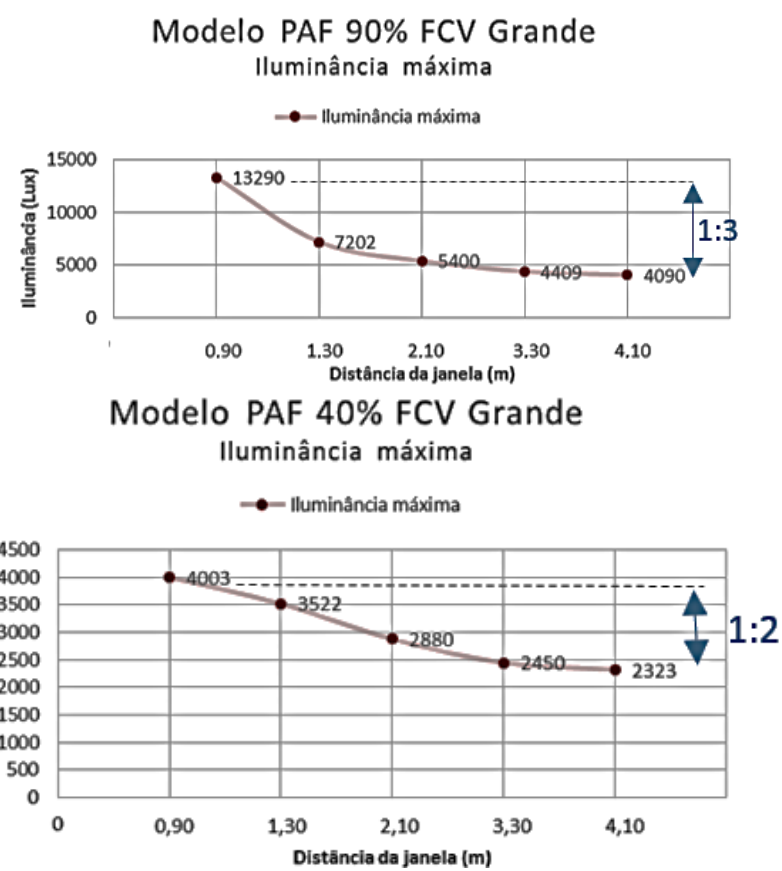




\section{UDI}

Os resultados indicam que o intervalo convencional de UDI diverge consideravelmente do intervalo proposto nas situações de grande luminosidade. Tal fato é evidenciado nos modelos que combinam PAF de $60 \%$ e $90 \%$ com FCV médio e grande, caracterizados pela maior disponibilidade de luz natural (Figuras 17 e 18). Nesses modelos, para o nível de 100 lux, o intervalo convencional de UDI chega a classificar mais de $80 \%$ das ocorrências como UDI excessivo. Sendo assim, esse percentual de ocorrência de luz natural é considerado inapropriado por estar acima da faixa de iluminação natural útil (Figura 18). Para o nível de 300 lux, o intervalo convencional classifica mais de $50 \%$ da luz natural como UDI excessivo, para o modelo PAF 90\% e FCV grande. Contudo, os modelos analisados caracterizam-se pela incidência de radiação totalmente difusa, sem grandes contrastes, característica considerada pela literatura como adequada e desejável. Essa situação é coerente com os resultados do intervalo proposto, em que as ocorrências supracitadas de $80 \%$ e $50 \%$ descartadas no intervalo convencional são consideradas como iluminação natural útil (Figura 18).

Essa divergência entre as métricas ocorre nos modelos para níveis luminosos de 100 lux e de 300 lux em situações de grande disponibilidade de luz. Quando os modelos não possuem grande luminosidade (PAF de $20 \%$ e $40 \%$ e FCV pequeno) ou quando é considerada a iluminância mínima de 500 lux (Figura 16), o UDI convencional e o proposto apresentam resultados semelhantes para a luz natural útil no ambiente. O modelo com iluminância intermediária, com PAF 40\% e FCV médio, possui discrepância de até $30 \%$ entre intervalo convencional e proposto para iluminância de 100 lux.

A Tabela 2 sintetiza os resultados de convergência da métrica UDI entre o intervalo convencional e o proposto, obtidos conforme as Figuras 16, 17 e 18. Evidencia-se a divergência da métrica UDI entre os métodos para as situações de 100 lux e de 300 lux, nos modelos de maior disponibilidade de luz natural (com FCV grande ou médio, e PAF de 40\%, 60\% e $90 \%)$.

\section{Conclusão}

O estudo contribui para a discussão de critérios mais apropriados para a análise de iluminação natural em climas tropicais, onde existe nível de iluminância consideravelmente superior a cidades de alta latitude, de onde advém as principais recomendações da literatura. Essa discussão é relevante no contexto brasileiro de difusão e discussão de normas de desempenho e eficiência energética como a NBR15575 (ABNT, 2008) e o Regulamento Técnico da Qualidade do Nível de Eficiência Energética de Edifícios Residenciais (RTQ-R) (INSTITUTO..., 2010b), visto que considera como questões não somente o atendimento mínimo de iluminância como também a uniformidade, além de ter um amplo contexto internacional, devido a sua larga aplicabilidade para cidades com alta luminosidade, onde geralmente são considerados os critérios e análises recomendados pela literatura sem verificação da adequação destes à situação do clima tropical.

Os resultados demonstram que o intervalo convencional de UDI tende a desconsiderar uma ocorrência significativa de luz natural em situação de grande luminosidade, recorrente em climas tropicais. Isso diminui o percentual de disponibilidade de luz natural nas avaliações de desempenho luminoso desses ambientes. É verificado que o intervalo proposto desconsidera valores com iluminação considerada excessiva quando indicado grande contraste (quando ultrapassa a relação de 1/10 entre iluminância mínima e máxima), o que não ocorreu em nenhum modelo simulado, visto que há incidência de radiação solar difusa abundante e o bloqueio da radiação solar direta em todos os modelos.

O DAmax calculado apresenta discrepâncias substanciais em relação ao DAmax gerado pelo programa. O primeiro é um critério com adaptação dos níveis mínimos e máximos de iluminância atingidos no ambiente, sendo, portanto, mais facilmente adaptável à realidade do clima tropical. O segundo considera apenas a relação de 1/10 em relação ao nível de iluminância mínimo requerido. O UDI proposto apresenta uma análise mais aproximada da disponibilidade de luz natural local e mais criteriosa quanto ao aproveitamento da luz natural para os ambientes localizados em climas tropicais.

Foram constatadas diferenças consideráveis entre o intervalo convencional e o proposto na indicação de uniformidade da luz natural e iluminação natural útil das métricas DAmax e UDI. O intervalo proposto tende a melhor representar a realidade do clima tropical e apresenta resultados mais coerentes das ocorrências. A métrica adotada pelo programa Daysim pode mascarar algumas situações, não considerando adequadas as situações onde pode existir iluminação natural difusa abundante e uniforme. Isso se torna mais evidente para situações onde o nível mínimo de projeto exigido é de 100 lux (para variável DAmax e UDI). Os resultados obtidos demonstram que é necessário adequar a forma de cálculo para esse contexto climático. 
Figura 16 - UDI, DA e DAmax dos modelos com FCV pequeno - intervalo convencional e intervalo proposto

MÉTODO CONVENCIONAL - PAF 20\% FCV Pequeno

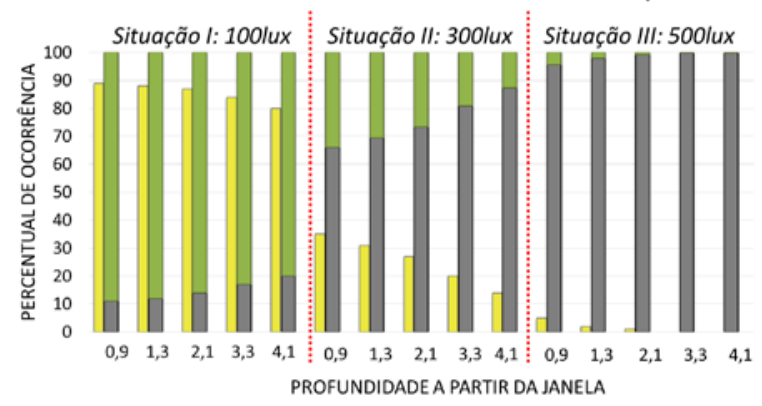

$\square \mathrm{DA} \backsim \mathrm{DAmax} \backsim \mathrm{DACAL} \square$ UDI insuficiente $₫$ UDI autônomo $₫$ UDI excessivo MÉTODO CONVENCIONAL - PAF 40\% FCV Pequeno

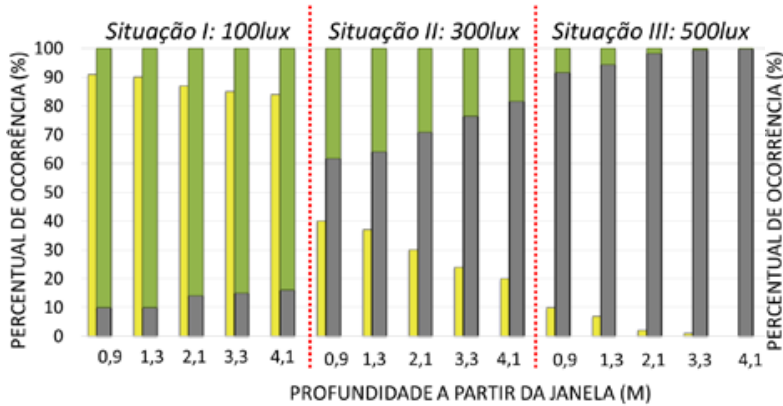

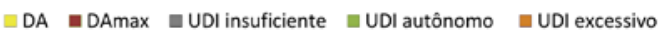
MÉTODO CONVENCIONAL - PAF 60\% FCV Pequeno

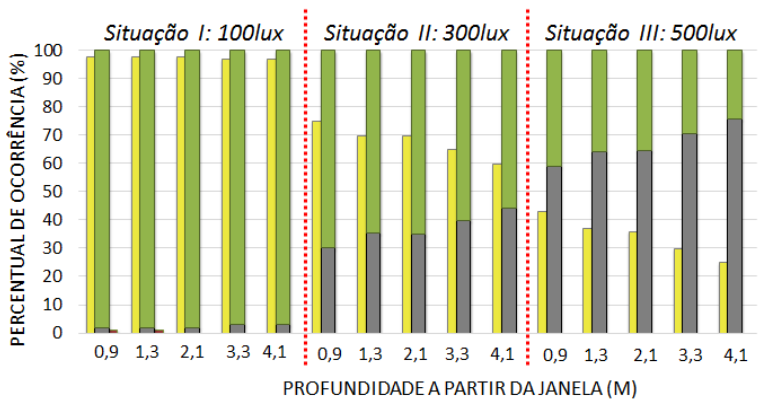

$\square$ DA घDAmax घUDI insuficiente घUDI autônomo घUDI excessivo

MÉTODO CONVENCIONAL - PAF 90\% FCV Pequeno

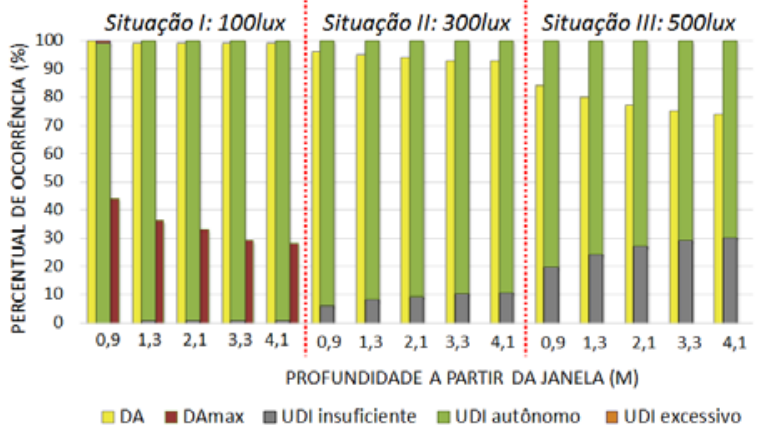

MÉTODO PROPOSTO - PAF 20\% FCV Pequeno

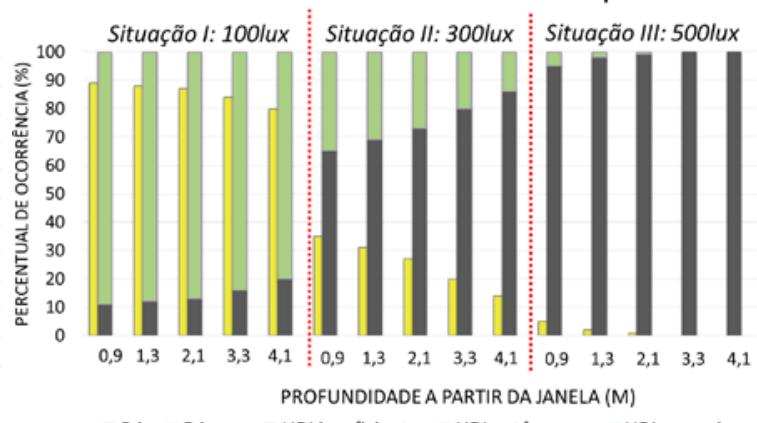

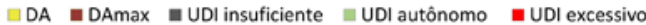
MÉTODO PROPOSTO - PAF 40\% FCV Pequeno

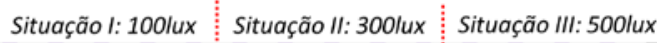

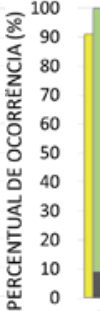

0,9

$$
\square
$$

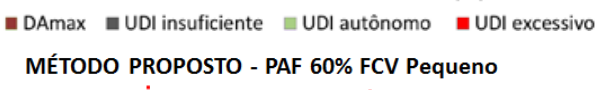

$$
100
$$

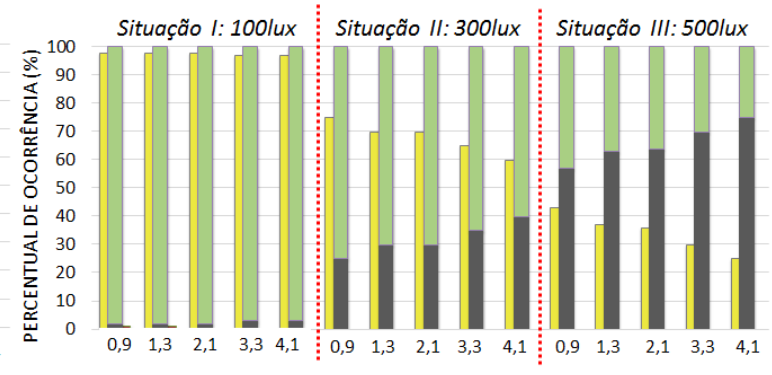

PROFUNDIDADEA PARTIR DA JANELA (M)

$\square$ DA $\square$ DAmax घUDI insuficiente $\square$ UDI autônomo @UDI excessivo

\section{MÉTODO PROPOSTO - PAF 90\% FCV Pequeno}

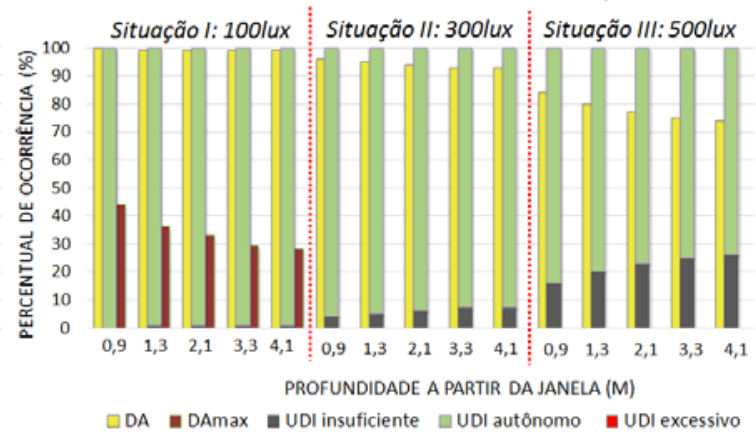


Figura 17 - UDI, DA e DAmax dos modelos com FCV médio - intervalo convencional e intervalo proposto MÉTODO CONVENCIONAL - PAF 20\% FCV Médio

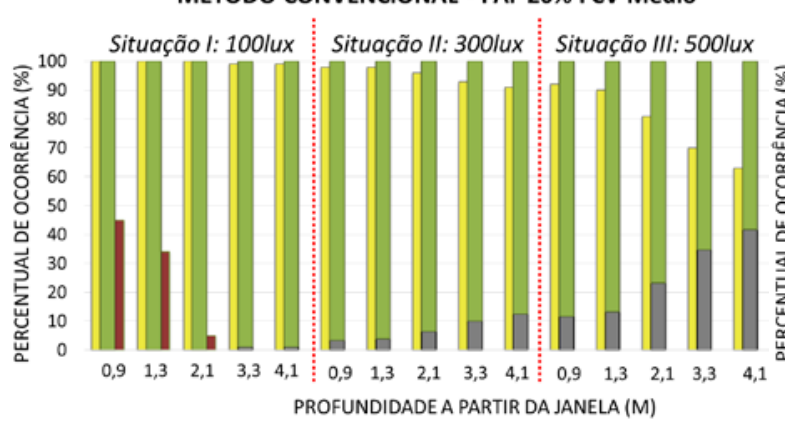

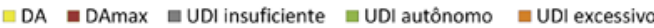
MÉTODO CONVENCIONAL - PAF 40\% FCV Médio

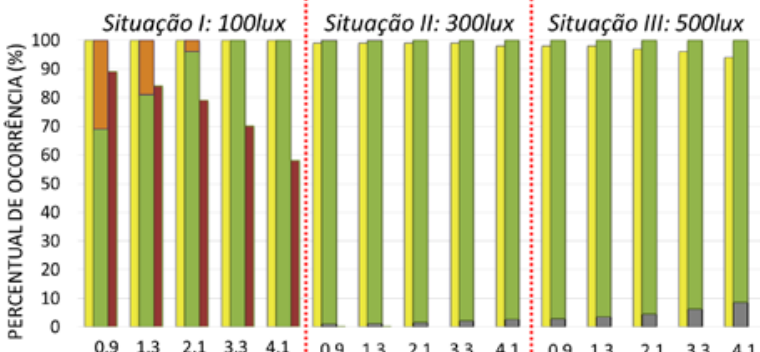
PROFUNDIDADE A PARTIR DA JANELA (M)

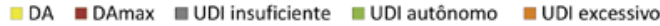
MÉTODO CONVENCIONAL - PAF 60\% FCV Médio

Situação l: 100lux Situação II: 300lux Situação III: 500lux

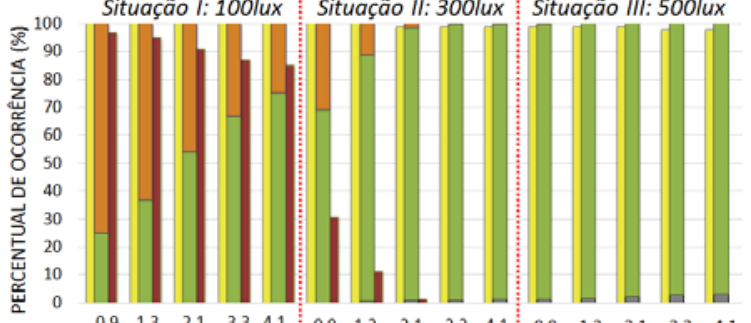

$\begin{array}{lllll:lllll:lllll}0,9 & 1,3 & 2,1 & 3,3 & 4,1 & 0,9 & 1,3 & 2,1 & 3,3 & 4,1 & 0,9 & 1,3 & 2,1 & 3,3 & 4,1\end{array}$ PROFUNDIDADEA PARTIR DA JANELA (M)

$\square \mathrm{DA} \backsim \mathrm{DAmax} \square \mathrm{UDl}$ insuficiente $\square$ UDl autônomo घUDl excessivo MÉTODO CONVENCIONAL - PAF 90\% FCV Médio

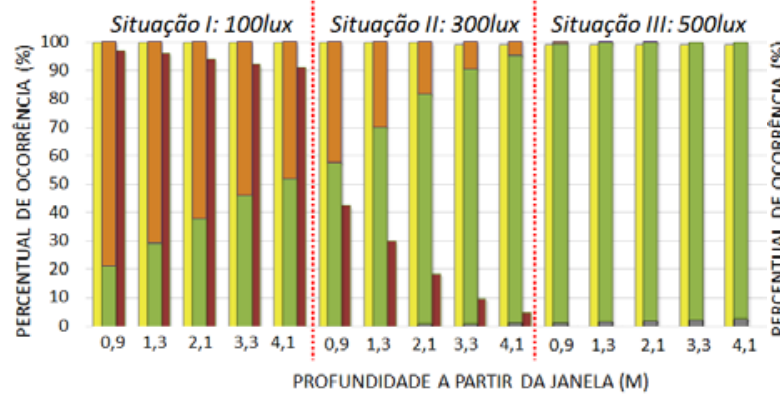

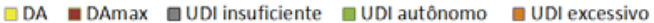

MÉTODO PROPOSTO - PAF 20\% FCV Médio

Situação I: 100lux Situaçãoll: 300lux : Situação III: 500lux

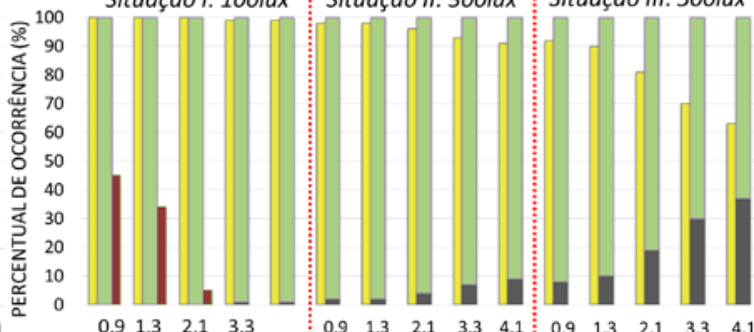

$\begin{array}{lllllllll:llllll}0,9 & 1,3 & 2,1 & 3,3 & 0,9 & 1,3 & 2,1 & 3,3 & 4,1 & 0,9 & 1,3 & 2,1 & 3,3 & 4,1\end{array}$ PROFUNDIDADEA PARTIR DA JANELA (M)

$\square \mathrm{DA}=\mathrm{DAmax}=\mathrm{UDl}$ insuficiente $=\mathrm{UDI}$ autônomo $=$ UDI excessivo MÉTODO PROPOSTO - PAF 40\% FCV Médio

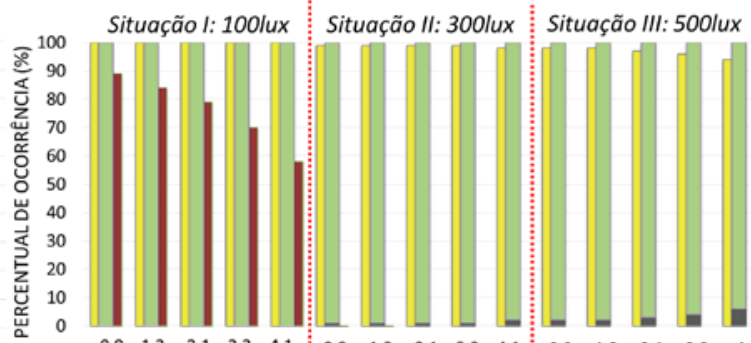

$\begin{array}{lllll:lllll:llllll}0,9 & 1,3 & 2,1 & 3,3 & 4,1 & 0,9 & 1,3 & 2,1 & 3,3 & 4,1 & 0,9 & 1,3 & 2,1 & 3,3 & 4,1\end{array}$ PROFUNDIDADE A PARTIR DA JANELA (M)

$\square \mathrm{DA}=\mathrm{DAmax}=\mathrm{UDl}$ insuficiente $=$ UDI autônomo = UDI excessivo MÉTODO PROPOSTO - PAF 60\% FCV Médio

Situação l: 100lux Situação II: 300lux Situação III: 500lux

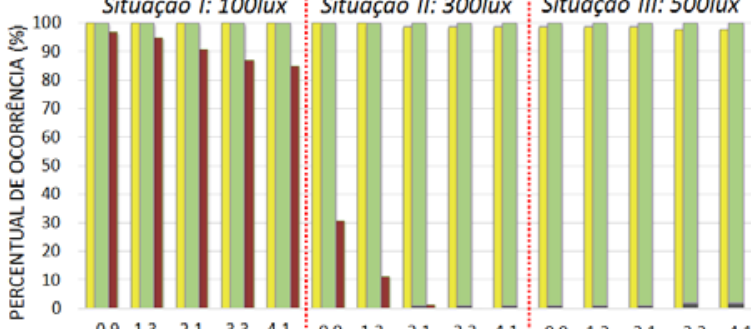

\begin{tabular}{lllll:lllll|llllll}
0,9 & 1,3 & 2,1 & 3,3 & 4,1 & 0,9 & 1,3 & 2,1 & 3,3 & 4,1 & 0,9 & 1,3 & 2,1 & 3,3 & 4,1
\end{tabular} PROFUNDIDADE A PARTIR DA JANELA (M)

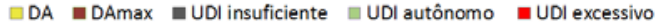
MÉTODO PROPOSTO - PAF 90\% FCV Médio

Situaçãol: 100lux Situação II: 300lux Situação III:500lux

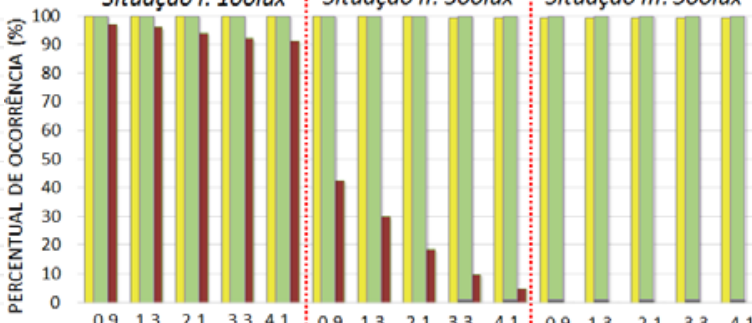

\begin{tabular}{lllll:lllll|lllll}
0,9 & 1,3 & 2,1 & 3,3 & 4,1 & 0,9 & 1,3 & 2,1 & 3,3 & 4,1 & 0,9 & 1,3 & 2,1 & 3,3 & 4,1
\end{tabular} PROFUNDIDADE A PARTIR DA JANELA (M)

DA DAmax GUDI insuficiente nUDI autônomo nDI excessivo 
Figura 18 - UDI, DA e DAmax dos modelos com FCV grande - intervalo convencional e intervalo proposto MÉTODO CONVENCIONAL - PAF 20\% FCV Grande
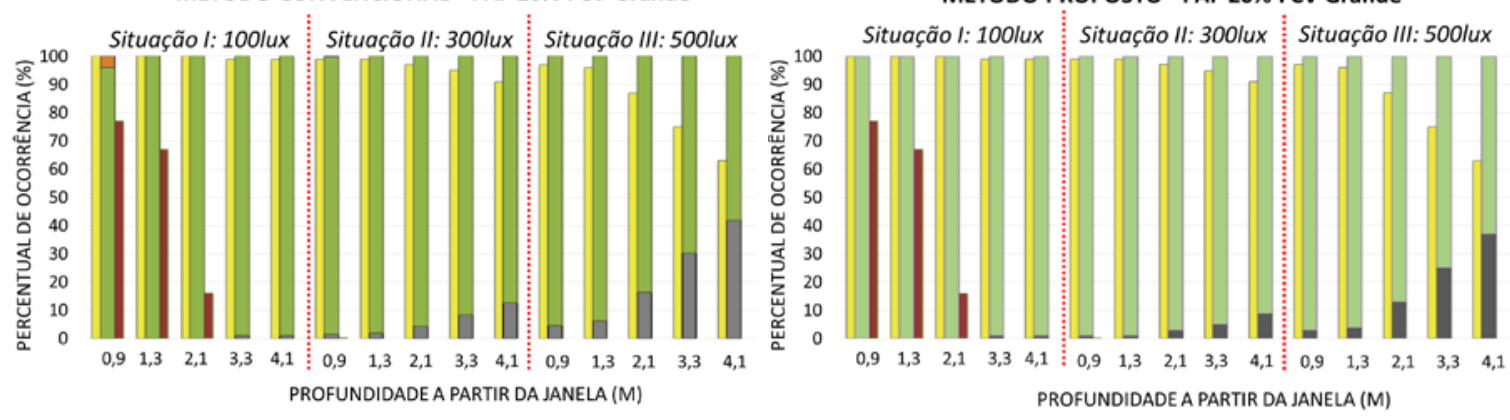

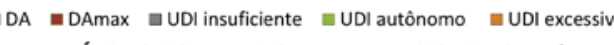
MÉTODO CONVENCIONAL - PAF 40\% FCV Grande

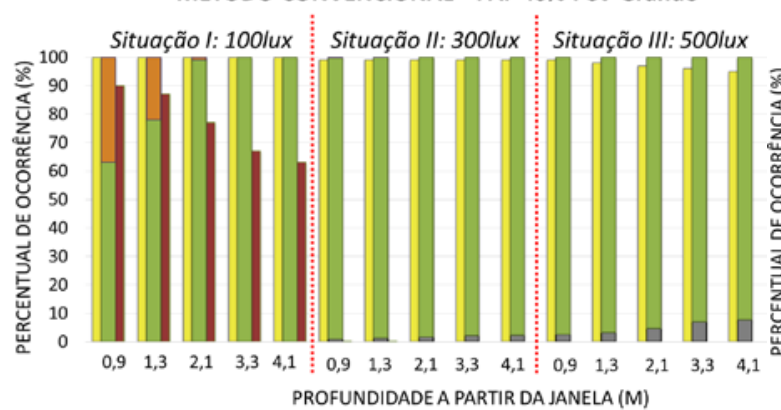

MÉTODO PROPOSTO - PAF 40\% FCV Grande

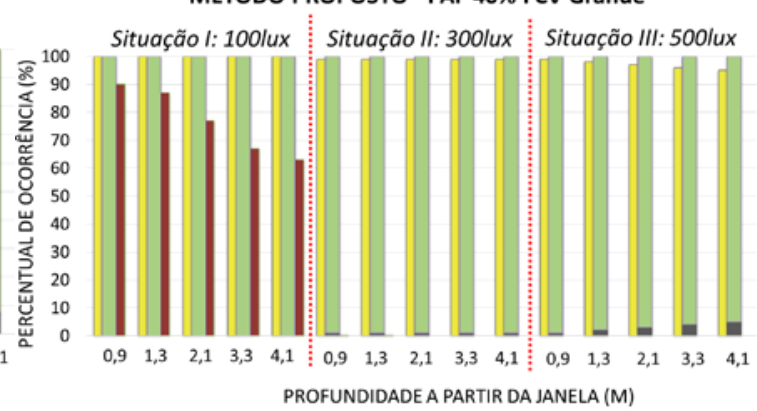

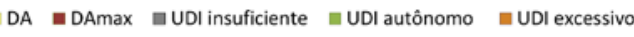
MÉTODO CONVENCIONAL - PAF 60\% FCV Grande

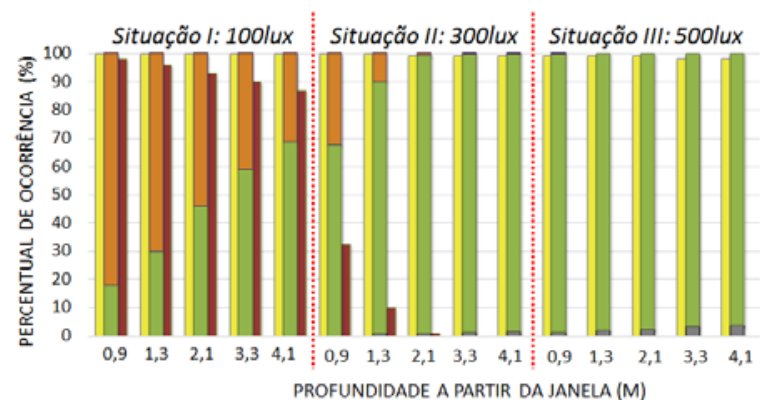

DA MÉTODO PROPOSTO - PAF 60\% FCV Grande

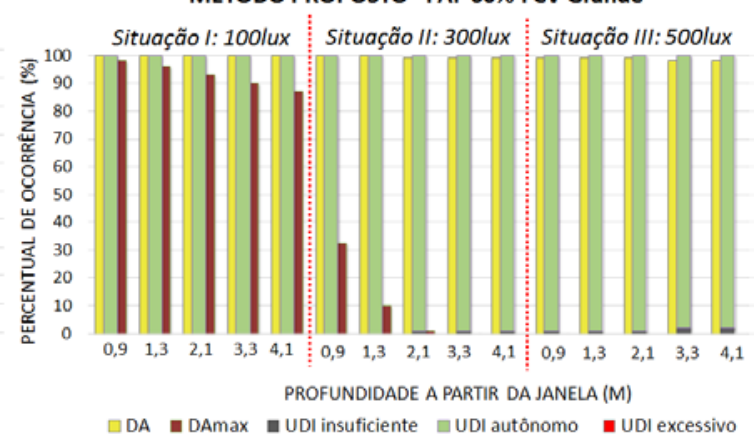

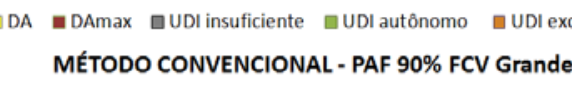

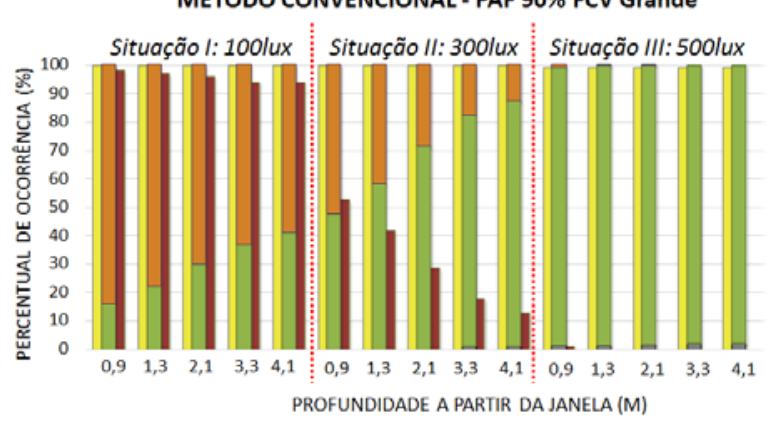

MÉTODO PROPOSTO - PAF 90\% FCV Grande

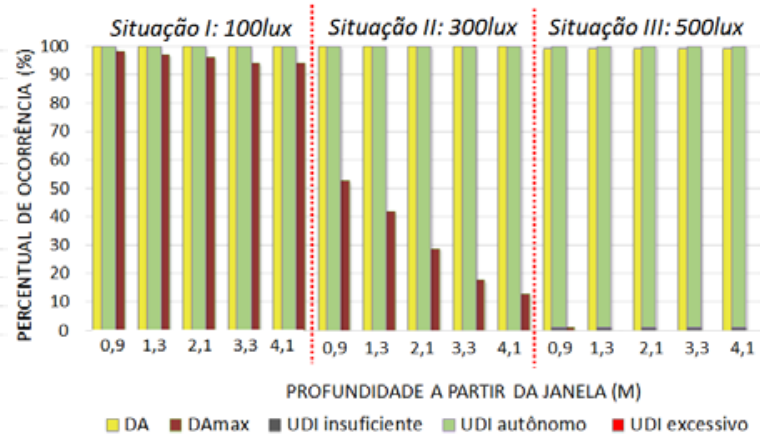

$\square D A \square D A m a x \quad \square U D I$ insuficiente $\square$ UDI autônomo $\square$ UDI excessivo

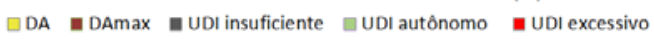


Tabela 2 - Indicação da divergência entre os métodos convencional e proposto - métrica UDI

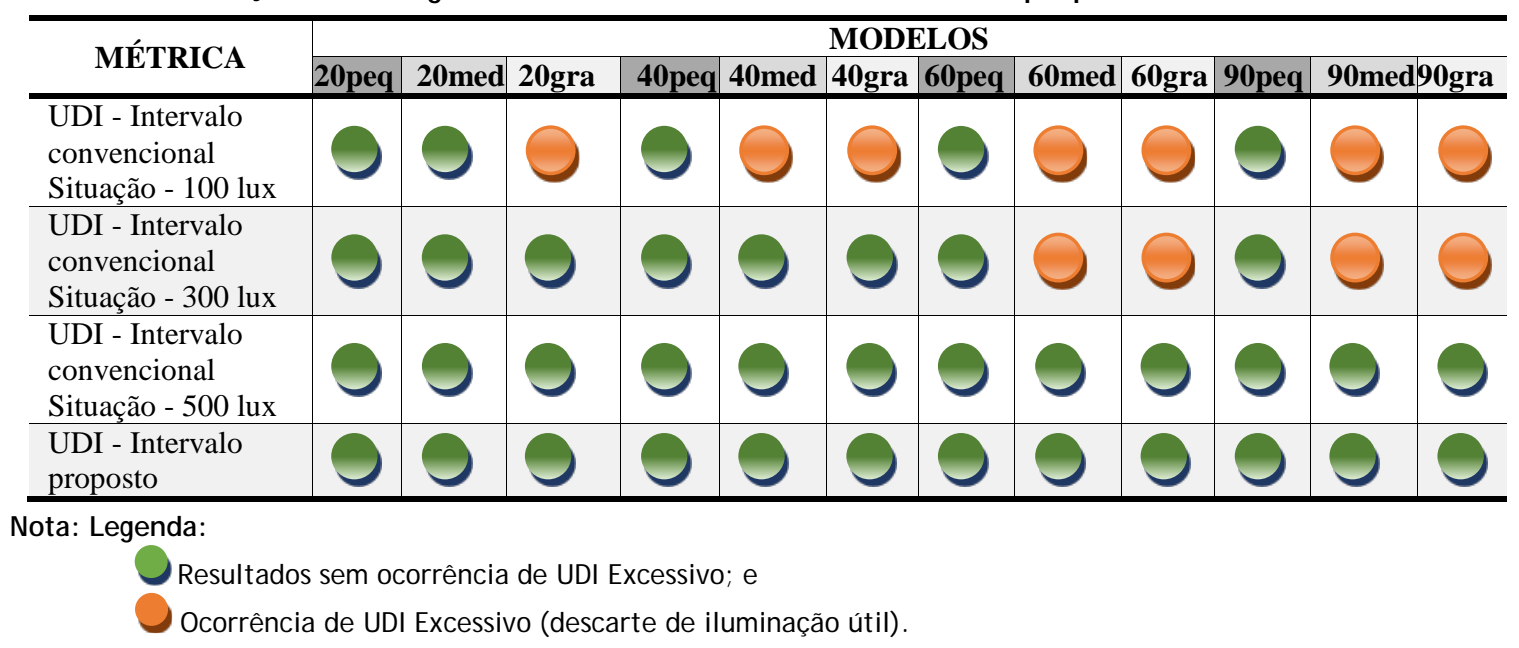

O cálculo mais adequado para climas tropicais deve considerar a uniformidade a partir da iluminância mínima encontrada no ambiente, e não da iluminância mínima preestabelecida de projeto. Os limites superiores de luz natural difusa e sem contratastes ainda são desconhecidos pela literatura para compor um limite invariável de UDI excessivo, sendo necessária sua readequação de acordo com o contexto.

São necessários estudos indicativos dos níveis de tolerância dos usuários em relação à iluminância máxima para cidades de grande luminosidade para respaldar a adoção de intervalos de DAmax e UDI, considerando os contextos climáticos.

A pesquisa tem como limitação principal a análise de modelos com aberturas voltadas apenas para orientação norte, com desempenho similar ao da orientação sul, não considerando situações com entrada de luz direta ou difusa das orientações leste e oeste.

\section{Referências}

ALBUQUERQUE, M. S. C. de; AMORIM, C. N. D. Iluminação Natural: indicações de profundidade-limite de ambientes para iluminação natural no Regulamento Técnico da Qualidade do Nível de Eficiência Energética de Edifícios Residenciais - RTQ-R. Ambiente Construído, Porto Alegre, v. 12, n. 2, p. 37-57, abr./jun. 2012.

\section{ASSOCIAÇÃO BRASILEIRA DE NORMAS} TÉCNICAS. NBR 15215-4: iluminação natural: parte 4: verificação experimental das condições de iluminação interna de edificações: método de medição. Rio de Janeiro, 2005.

\section{ASSOCIAÇÃO BRASILEIRA DE NORMAS}

TÉCNICAS. NBR 15575: edifícios habitacionais de até cinco pavimentos: desempenho parte 1: requisitos gerais: parte 1: requisitos gerais. Rio de Janeiro, 2008.

ASSOCIAÇÃO BRASILEIRA DE NORMAS

TÉCNICAS. NBR 5413: iluminância de interiores. Rio de Janeiro, 1992.

ASSOCIAÇÃO BRASILEIRA DE NORMAS TÉCNICAS. NBR ISO/CIE 8995-1: iluminação de ambientes de trabalho: parte 1: interior. Rio de Janeiro, 2013.

\section{AUTODESK. AutoCad. Califórnia 2013.}

CARVALHO, J. et al. The Inadequacy of Rulesof-Thumb to Determine Daylight Zone Depth for Different Shading Systems in Tropical Climate. In: PLEA, 2016, Los Angeles, Cities, Buildings People: Toward Regenerative Environments. Proceedings... Los Angeles, 2016.

\section{CARVALHO, J. P. V. de. Simulação do}

Desempenho Luminoso Para Salas de Aula em Natal-RN. Natal, 2014. Dissertação (Mestrado em Arquitetura e Urbanismo) - Departamento de Arquitetura e Urbanismo, Universidade Federal do Rio Grande do Norte, Natal, 2014.

CHATZIDIMITRIOU, A.; YANNAS, S.

Microclimatic Studies of Urban Open Spaces in Northenrn Greece. In: PLEA, 2004, $21^{\text {st }}$., 2004. Proceedings... Eindhoven, 2004.

CINTRA, M. S. Arquitetura e Luz Natural: a influência da profundidade de ambientes em edificações residenciais. Brasília: UnB, 2011. 
CIRÍACO, C. H. de O. Um Lugar Onde os Espaços Ensinam: anteprojeto arquitetônico de uma escola infantil e fundamental I em Parnamirim/RN. Natal, 2016. 180 f. Dissertação (Mestrado Profissional em Arquitetura e Urbanismo) - Departamento de Pós-Graduação em Arquitetura e Urbanismo, Universidade Federal do Rio Grande do Norte, Natal, 2016.

CLARO, A. Apolux IV. Florianópolis: Procel; Sistema Eletrobrás, 2016.

COLLISCHONN, E.; FERREIRA, C. V. de O. O Fator de Visão do Céu e Sua Influência Sobre as Características Térmico-Higrométricas Intraurbanas em Pelotas/RS, Brasil. Geographia Meridionalis, Pelotas, v. 1, p. 160-178, 2015.

DESIGNBUILDER SOFTWARE LTD. DesignBuilder. 2000-2009.

DIAS, A. R. D. Análise do Impacto do Sombreamento Vegetal no Conforto Termoluminoso de Edificações no Clima Quente e Úmido. Natal, 2016. Dissertação (Mestrado em Arquitetura e Urbanismo) Programa de Pós-Graduação em Arquitetura e Urbanismo, Universidade Federal do Rio Grande do Norte, Natal, 2016.

DOE, U.S. Department of Energy's Energy

Plus: Building Technologies Office (BTO). The National Renewable Energy Laboratory (NREL). 2012.

GONZÁLEZ, J.; FIORITO, F. Daylight Design of Office Buildings: Optimisation of external solar shadings by using combined simulation methods. Buildings, v. 5, n. 2, p. 560-580, 2015.

INSTITUTO NACIONAL DE METROLOGIA, QUALIDADE E TECNOLOGIA. Portaria no 372, de 17 de setembro de 2010. Brasília, 2010a.

INSTITUTO NACIONAL DE METROLOGIA, QUALIDADE E TECNOLOGIA. Requisitos

Técnicos da Qualidade para o Nível de Eficiência Energética de Edifícios Comerciais, de Serviços e Públicos. Anexo da portaria INMETRO n 372 / 2010. Brasília, 2010b.

LAMBERTS, R. et al. Anexo da Portaria Inmetro no 163 /2009: RTQ-C, Regulamento Técnico da Qualidade do Nível de Eficiência Energética de Edifícios Comerciais, de Serviços e Públicos. Rio de Janeiro, 2009. Disponível em: <www.inmetro.gov.br>. Acesso em: 12 dez. 2017.
LEDER, S. M. Ocupação Urbana e Luz Natural: proposta de parâmetro de controle da obstrução do céu para garantia da disponibillidade à luz natural. Florianópolis, 2007. Tese (Doutorado em Engenharia Civil) - Pós-Graduação em Engenharia Civil, Área de concentração Construção Civil, Universidade Federal de Santa Catarina, Florianópolis, 2007.

LEDER, S. M.; PEREIRA, F. O. R.; CLARO, A. Janela de Céu Preferível: proposição de um parâmetro para controle da disponibilidade de luz natural no meio urbano. Ambiente Construído, Porto Alegre, v. 8, n. 1, p. 89-104, jan./mar. 2008.

MARCHIS, A. et al. Relação Entre Iluminação Natural e Eficiência Energética em Edifício do Campus Universitário da UnB: elementos determinantes. In: ENCONTRO NACIONAL DE CONFORTO NO AMBIENTE CONSTRUÍDO, 11.; ENCONTRO LATINO-AMERICANO DE CONFORTO NO AMBIENTE CONSTRUÍDO, 7., Búzios, 2011. Anais... Búzios, 2011.

MARDALJEVIC, J. et al. Daylight Metrics for Residential Buildings. In: SESSION OF THE CIE, 27., África do Sul, 2011. Proceedings... África do Sul, 2011.

MARQUES, M. P. de P. Análise da Eficiência de Elementos de Proteção Solar em Relação ao Sombreamento e a Iluminação Natural Estudo de Caso: salas de aula do Campus I da UFPB. João Pessoa, 2012. Dissertação (Mestrado em Engenharia Urbana e Ambiental) - Programa de Pós-Graduação em Engenharia Urbana e Ambiental, Universidade Federal da Paraíba, João Pessoa, 2012.

MARSH, A. Solar Tool 2010. Plugin do programa Ecotect versão 2010.

MORENO, V. P. C. Estratégias Para Obtenção de Adequada Iluminação Natural em Escolas: uma análise de sistemas de aberturas para Natal/RN. Natal, 2015. Dissertação (Mestrado em Arquitetura e Urbanismo) - Departamento de PósGraduação em Arquitetura e Urbanismo, Universidade Federal do Rio Grande do Norte, Natal, 2015.

NABIL, A.; MARDALJEVIC, J. Useful Daylight

Illuminance: a new paradigm for assessing daylight in buildings. Leicester: Sage Journals, 2005.

NABIL, A.; MARDALJEVIC, J. Useful Daylight Illuminances: a replacement for daylight factors. Energy and Buildings, v. 37, n. 8, p. 905-913, jul. 2006. 
O’CONNOR, J. et al. Tips For Daylighting With Windows: the integrated approach. Berkeley: Ernest Orlando Lawrence Berkeley National Laboratory, 1997.

PAULA, D. C. J. de et al. Fator de Visão de Céu e Sombreamento Arbóreo em Área Verde Urbana de Clima Tropical. REVSBAU, Piracicaba, v. 11, p. 18-31, 2016.

REINHART, C. Daylight Availability and Manual Litghing Control in Office Biuldings: simulation studies and analysis of measurements. Düsseldorf, 2001. Thesis (Doctor of Engineering) - Faculty of Architecture, University of Karlsruhe, Düsseldorf, 2001.

REINHART, C. Daysim 3.1. Cambridge: Harvard University, 2010a.

REINHART, C. F.; BOURGEOIS, D.; DUBROUS, F. Lightswitch: a model for manual control of lighting and blinds. In: CONFERENCE CISBAT, Lausanne, 2003. Proceedings...

Lausanne: NRC Publications Archive (NPArC), 2003.

REINHART, C. F.; MARDALJEVIC, J.; ROGERS, Z. Dynamic Daylight Performance Metrics For Sustainable Building Design. Leukos, Ottawa, V. 3, p. 7-31, 2006.

REINHART, C. Tutorial on the Use of Dayism Simulations for Sustainable Design. Cambridge: Harvard University, 2010b.
RORIZ, M. RN_Natal.epw. São Carlos: Roriz Bioclimática, 2009.

RORIZ, M. Arquivos Climáticos de Municípios Brasileiros. São Carlos: ANTAC, 2012. Grupo de Trabalho sobre Conforto e Eficiência Energética de Edificações.

RUCK, N. et al. Daylitgh in Buildings: ECBCS Annex 29. Reino Unido, 2010.

SOUZA, L. C. L. de et al. Fator de Visão do Céu e Intensidade de Ilhas de Calor na Escala do Pedestre. Ambiente Construído, Porto Alegre, v. 10, n. 4, p. 155-167, out./dez. 2010.

SOUZA, R V. G. de. Desenvolvimento de Modelos Matemáticos Empíricos Para a Descrição dos Fenômenos de Iluminação Natural Externa e Interna. Florianópolis, 2004. Tese (Doutorado em Engenharia Civil) - Programa de Pós-Graduação em Engenharia Civil, Universidade Federal de Santa Catarina, Florianópolis, 2004.

\section{Agradecimentos}

Os autores agradecem à Coordenação de Aperfeiçoamento de Pessoal de Nível Superior (CAPES) e ao Conselho Nacional de Desenvolvimento Científico e Tecnológico (CNPq) pela concessão das bolsas de estudo de mestrado e doutorado.

\section{Alice Ruck Drummond Dias}

Centro de Tecnologia | Universidade Federal do Rio Grande do Norte | Av. Senador Salgado Filho, 3000, Campus Universitário, Lagoa Nova | Natal - RN - Brasil | CEP 59076-000 | Tel.: (84) 3215-3722 | E-mail: alice@edificioeficiente.com

J uliana Portela Vilar Carvalho

Departamento de Arquitetura e Urbanismo, Centro de Tecnologia | Universidade Federal do Rio Grande do Norte |

E-mail: juliportela@gmail.com

\section{Viviane Diniz Hazboun}

Departamento de Arquitetura e Urbanismo, Centro de Tecnologia | Universidade Federal do Rio Grande do Norte |

E-mail: vivianehazboun@gmail.com

\section{Aldomar Pedrini}

Departamento de Arquitetura e Urbanismo, Centro de Tecnologia | Universidade Federal do Rio Grande do Norte |

E-mail: apedirni@ufrnet.ufrn.br

\section{Revista Ambiente Construído}

Associação Nacional de Tecnologia do Ambiente Construído

Av. Osvaldo Aranha, 99 - 3o andar, Centro

Porto Alegre - RS - Brasil

CEP $90035-190$

Telefone: +55 (51) 3308-4084

Fax: +55 (51) 3308-4054

www. seer. ufrgs. br/ ambienteconstruido

E-mail: ambienteconstruido@ufrgs.br 